\title{
What's the Talk in Brussels? Leveraging Daily News Coverage to Measure Issue Attention in the European Union
}

\author{
Michal Ovádek* Nicolas Lampach ${ }^{\dagger}$ and Arthur Dyevre
}

November 7, 2019

\begin{abstract}
Research on issue attention in the European Union has focused on the prominence of EU integration in domestic politics and media and, at EU level, on the salience of individual issues and legislative files, often in relation to lobbying. Existing EU-level measures of issue saliency, though, are limited in scope and periodicity and tend to reflect the policy priorities of a single institutional actor rather than that of the broader EU elite sphere. We present an alternative measure of issue attention leveraging the quasi-institutional nature of the Agence Europe daily bulletin which provides comprehensive but independent news coverage of EU affairs. We use text-mining techniques, including dynamic topic modelling, in combination with manual classification to map issue prevalence between 1979 and 2018. In addition to reporting validation results, we illustrate how our measure relates to other indicators of EU agenda formation and explain how researchers can make use of our new dataset.
\end{abstract}

Keywords: Issue attention, Media, Dynamic topic model, Validation JEL Classification: C19, C59, H79, K10

Word count: 7767

* Corresponding author: KU Leuven, Faculty of Law, Centre for Legal Theory and Empirical Jurisprudence, 45 Tiensestraat, 3000 Leuven, Belgium. E-mail: michal.ovadek@kuleuven. be.

${ }^{\dagger}$ KU Leuven, Faculty of Law, Centre for Legal Theory and Empirical Jurisprudence, 45 Tiensestraat, Leuven, Belgium. E-mail: nicolas.lampach@kuleuven.be.

${ }_{\ddagger}^{\ddagger}$ KU Leuven, Faculty of Law, Centre for Legal Theory and Empirical Jurisprudence, 45 Tiensestraat, Leuven, Belgium. E-mail: arthur.dyevre@law.kuleuven.be. 


\section{Introduction}

What issues receive political attention, or not, is a crucial aspect of politics. Political attention is a scarce and precious good, for which aspiring agenda influencers must compete along with institutionalized agenda-setters. So, since agenda formation affects, either directly or indirectly, virtually all facets of politics, it is not surprising that political scientists have expended considerable efforts on mapping and explaining how policy agendas change (Baumgartner et al., 2006, Baumgartner and Jones, 1993; Princen and Rhinard, 2006), issues and their frames evolve (Carmines and Stimson, 1989, Diez-Medrano, 2004) and how democratic institutions respond to public demands and concerns (Alexandrova et al., 2016; Sorace, 2018).

European Union (EU) studies are no exception to the quest for reliable and comprehensive indicators of issue attention. Much of the literature on agenda formation in the context of EU affairs has concerned itself with the salience of EU integration in domestic politics and media (Rauh, 2014, Wonka, 2016, Veen, 2011; Netjes and Binnema, 2007; Adam and Eschner, 2008; Peter and De Vreese, 2004, Koopmans and Pfetsch, 2006: Diez-Medrano, 2004). Owing to the absence of "a genuinely supranational public sphere on the European level" (Koopmans, 2007; Risse, 2010, 185), measuring the degree of "Europeanization" of domestic politics has been the principal preoccupation of this strand of research. At EU level, meanwhile, researchers have concentrated on the salience of individual issues and legislative files, often in connection with lobbying efforts (Beyers et al., 2018; De Bruycker and Beyers, 2015; Klüver, 2011; Dür and Mateo, 2014). As with agenda research in other contexts, the development of a general measure of issue attention has had to grapple with the difficulty of measuring salience in a comprehensive manner (Wlezien, 2005), either due to prohibitive cost of measurement techniques (surveys, expert interviews, human coding) or the lack of sufficiently comprehensive data (Warntjen, 2012). Using European Council and European Commission documents, though, researchers have evolved actor-based indicators of agenda formation. Among these is the European Union Policy Agendas Project (Alexandrova et al. 2014), which represents, to date, the most comprehensive attempt to measure issue attention at EU level. The dataset covers a wide range of policies across four decades and constitutes, without any doubt, a major contribution to the study of agenda-setting in the EU context. Still, it exhibits important limitations. First, it is exclusively based on the items appearing in European Council conclusions. Yet what matters to the European Council may not matter for other EU actors, and vice-versa. Researchers should therefore be wary of using it as more than a measure of Council agenda priority. Second, European Council conclusions emphasize high politics where national governments wish to set general guidelines and objectives for the bloc. Yet for 
many research questions, such as the influence of lobby groups on particular policies or the comparative policy responsiveness of EU institutions on specific issues, researchers need a measure that captures both high and low politics and is independent of EU institutions. More broadly, what they need is a measure that captures issue attention in the Brussels-bound, EU elite sphere that encompasses Commissioners, MEPs, EU civil servants, diplomats, policy experts, EU contractors, consultants, pressure groups and NGOs, as well as national government representatives.

In this paper, we undertake to construct such a measure by leveraging text data from the Agence Europe bulletin (AEB). AEB, we argue, is a "quasi-institutional" news outlet which caters to EU policy wonks, civil servants and lobbyists. Published daily, it covers all policy areas within the remit of EU competences along with broader foreign policy and business news. The broad scope of AEB ensures that it captures low as well as high politics. Analysing the entire universe of English-language AEB from 1979 to 2018, we apply text-mining techniques, including dynamic topic modelling, to construct a detailed classification of the bulletins' contents. The resulting dataset provides a measure of the proportion of 75 machine-generated topics organized into 19 manually defined meta-categories 1 We validate our indicator using a random sample of human-coded bulletins. Besides showing how our measure of issue attention relates to other measures of EU agenda formation, we provide illustrations of how particular agenda items track international developments and critical junctures in the European integration process.

The paper proceeds as follows. Section 2 discusses the literature on issue attention. Section 3 provides some context regarding the documents forming our corpus and serving as basis for the construction of our indicator, while Section 4 explains our methodology. Section 5 presents the resulting measure, which we name "EUSSUE". Section 6 reports the results of our validation and Section 7 examines how EUSSUE compares to the Agendas Project. Finally, Section 8 links our measure to indicators concerning climate change, the Eurozone crisis, the European migrant crisis and the Syria conflict.

\section{Issue Attention in the EU}

Issue attention, agenda formation or issue saliency - we use these terms interchangeably ${ }^{2}$ - can be measured in a variety of ways. A useful distinction is between generic and actor-centred measures (Beyers et al. 2018). Actor-centred indicators approach

\footnotetext{
${ }^{1}$ The textual corpora (.txt and .RData) and time-series data (.dta, .csv and RData file) of the EUSSUE measure can be downloaded from the masked for review repository.

${ }^{2}$ For a conceptual elaboration of these notions see Beyers et al. (2018) and Netjes and Binnema (2007).
} 
issue saliency from the viewpoint of aspiring agenda influencers or institutionalized agenda setters. This is the approach adopted by researchers who have constructed measures of issue prevalence from European Council, Council of the European Union and European Commission files (Alexandrova, 2017; Alexandrova et al., 2016, 2014, Carammia et al., 2016; Osnabrügge, 2015, Häge, 2016), European Parliament speeches (Greene and Cross, 2017) or, at the domestic level, from debates in the legislature (Rauh, 2014; Wonka, 2016) or items in party manifestos (Veen, 2011). This approach has the advantage of being both analytically and empirically tractable, in addition to having relevance for various strands of research on EU politics. Each EU institution produces its own line of policy documents and communications which scholars have been able to dissect and interpret as issue attention Alexandrova et al., 2014; Greene and Cross, 2017; Osnabrügge, 2015; Häge, 2016). ? $^{3}$ The same holds for electoral manifestos and legislative debates (Rauh, 2014, Wonka, 2016, Veen, 2011). In contrast to actor-centred measures, generic measures seek to capture issue attention in the broader mediatized public sphere, assuming that this sphere is imperfectly controlled and transcends the priorities of individual agenda-setters. "Europeanization" studies that aim to assess the attention paid to the EU in domestic media (Adam and Eschner, 2008; Peter and De Vreese, 2004, Koopmans and Pfetsch, 2006; Diez-Medrano, 2004) typically follow this line of inquiry.

A comparison of the domestic and EU-level literatures on issue attention reveals an interesting disparity. Whereas research on issue attention at the domestic level features both generic and actor-centred approaches, the EU-level literature has considered only the latter. The underlying reason for this asymmetry may seem obvious. The EU lacks an autonomous public sphere (Koopmans, 2007, Risse, 2010, 185). So actorbased indicators may seem to adequately capture the items that define the agenda in Brussels. The EU Policy Agendas Project is predicated on the notion that the European Council is the most powerful agenda-setter in the EU context Alexandrova et al. 2014). Thus, what the EU pays attention to should somehow find its way into European Council conclusions, or alternatively into Commission documents or European Parliament speeches.

We believe, however, that actor-centred measures of agenda formation miss important aspects of the EU-level policy debate. While the EU lacks an autonomous public sphere, Commissioners, MEPs, EU civil servants, diplomats, policy experts, EU contractors, consultants, pressure groups, NGOs, and national government representatives operating in the Brussels-bound "EU bubble"(Busby, 2013) form what we may call an "elite sphere". What participants in this sphere debate and discuss goes be-

\footnotetext{
${ }^{3}$ The variance in issue attention among different institutions is itself an object of research (Alexandrova 2017).
} 
yond what a particular EU institution formally puts on its agenda. EU institutions are typically self-focused when articulating their policy priorities, as research comparing the Commission and the European Council has shown (Alexandrova, 2017). Moreover, what they choose to prioritize partly reflects their position in the policy-making process. European Council conclusions set broad goals and articulate general guidelines, which the Commission, the European Parliament and the Council of the European Union then work to implement (Alexandrova et al. 2012). By contrast, while issues debated in the EU elite sphere should be expected to include the items of high politics placed on the European Council's agenda in the ongoing policy cycle, they should also encompass many low-politics topics and sub-topics.

We would like a generic, EU-level measure of issue attention to cover all these items while minimizing the institutional biases associated with actor-centred measures. In the following sections, we undertake to construct and validate such a measure.

\section{The Agence Europe Bulletin}

We propose to construct a generic indicator of issue attention from the AEB. Founded in 1953, originally published in French and from 1979 onward also in English, the AEB specializes in news relating to EU activities and institutions. The AEB sees itself as the leading source of information on European integration:

"For 66 years now, Agence Europe has been widely considered THE source (some might say the 'Bible') of information on European economic and political integration.' ${ }^{4}$

Stressing its prominence in the EU elite sphere, some scholars have described the AEB as a "quasi-institution" (Fougier, 2010, Bastin, 2002; Marthoz, 2008). The bulletin is an elite-sphere publication both for and about EU decision makers. AEB journalists and correspondents are policy specialists while EU civil servants, Brussels-bound diplomats and EU policy experts constitute the bulk of AEB's readership (Fougier, 2010). This specialized, policy orientation is reflected in the breadth and dry descriptiveness of the bulletins. Aside from institutional and policy developments - which capture change in policy agendas (Princen and Rhinard, 2006, Princen, 2007, 2011, Peters, 1994) - bulletins also carry industry and economic news, in particular those tied to EU affairs. While the AEB along with its leading journalists are associated with a soft-federalist editorial line and EU officials are often their main source of information (Fougier, 2010), AEB is financially and organisationally independent of

\footnotetext{
${ }^{4}$ See website https://agenceurope.eu/en/about.html
} 
EU institutions. In early decades, the AEB sometimes re-printed institutional reports which could skew an individual issue towards the frames favoured by its institutional author. Nonetheless, the vast majority of bulletins consist of news items reporting on EU developments without using emotionally charged language and this largely descriptive tone is consistent over time $5^{5}$ Opinion pieces (including editorials) represent a very small fraction of the contents of the bulletins.

While political and media attention are, arguably, co-constitutive (Boydstun, 2013), we believe that the AEB provides a comprehensive and relatively objective measure of issue attention. This presumption rests on the small and specialized nature of the AEB's readership. First, the AEB reports on issues which are not sufficiently newsworthy for mass media but of interests to EU civil servants and policy experts. The resulting breadth of coverage makes the AEB suitable for serving as a basis for a general survey of topic attention. Second, its small, specialized audience makes the AEB unable to shape public opinion. Obviously, the AEB is not a publication for the masses. The AEB's journalistic style is descriptive rather than investigative (Fougier, 2010). So political actors at the EU level are relatively safe to ignore its reporting 6 In consequence, it seems reasonable to assume that AEB comprehensive coverage of EU affairs is comparatively less distorted by the pressures of electoral and political cycles and the desire to influence voters than transnational mass outlets - such as the Financial Times, the Guardian and the Economist - or, for that matter, national newspapers and TV broadcasters.

While the EU's elite sphere has seen the emergence of other news outlets - most notably euobserver, Euractiv and Politico - and their degree of overlap with the AEB is a question that future research might deem worth investigating, these outlets do not offer the temporal coverage of the AEB. The English version of the AEB employed in the construction of our measure of issue attention goes back to 1979. By comparison, the olded rivals of the AEB, Euractiv and Euractiv, were launched in respectively 1999 and 2000 .

\section{Data and Methodology}

This Section explains how digitized versions of the bulletins were obtained; how these texts were pre-processed to facilitate computer-aided analysis and how we combine probabilistic topic modelling and human classification to construct our indicator.

\footnotetext{
${ }^{5}$ We report a minor sentiment analysis exercise in the Appendix.

${ }^{6}$ Even the increased politicization of EU affairs and the emergence of rival outlets, such as Politico, Euractiv and eubserver has made little difference to AEB's descriptive style of reporting (Fougier, 2010).
} 


\subsection{Data: AEB, 1979-2018}

Our issue attention measure is derived from the entire universe of bulletins $(\mathrm{N}=9546)$ published in English during the period 1979-2018. By relying on a single type of publication from a single media source we strive to minimize unwanted heterogeneity and maximize temporal consistency in the underlying text data. Between 1979 and 2000 the textual data is available in scanned form courtesy of a digitization project conducted by the European University Institute Library. From 2000 onward the data was sourced in digital form from the website of Agence Europe.7

The fact that the data prior to 2000 comes from scans of printed publications, as opposed to HTML websites, could introduce unwanted distortion to our measure, as our topic modelling could pick up on technical differences between the two sets of documents. While we acknowledge that the pre-2000 data does not have the perfect quality of the electronically published documents, we strived to apply the best available optical character recognition (OCR) and image conversion techniques to minimize data loss. We point out that 19 bulletins from the early period are missing entirely. Depicting the number of words of each document, Figure 1 suggests the data retrieval process has not resulted in a systematically biased corpus.

7 https://agenceurope.eu 


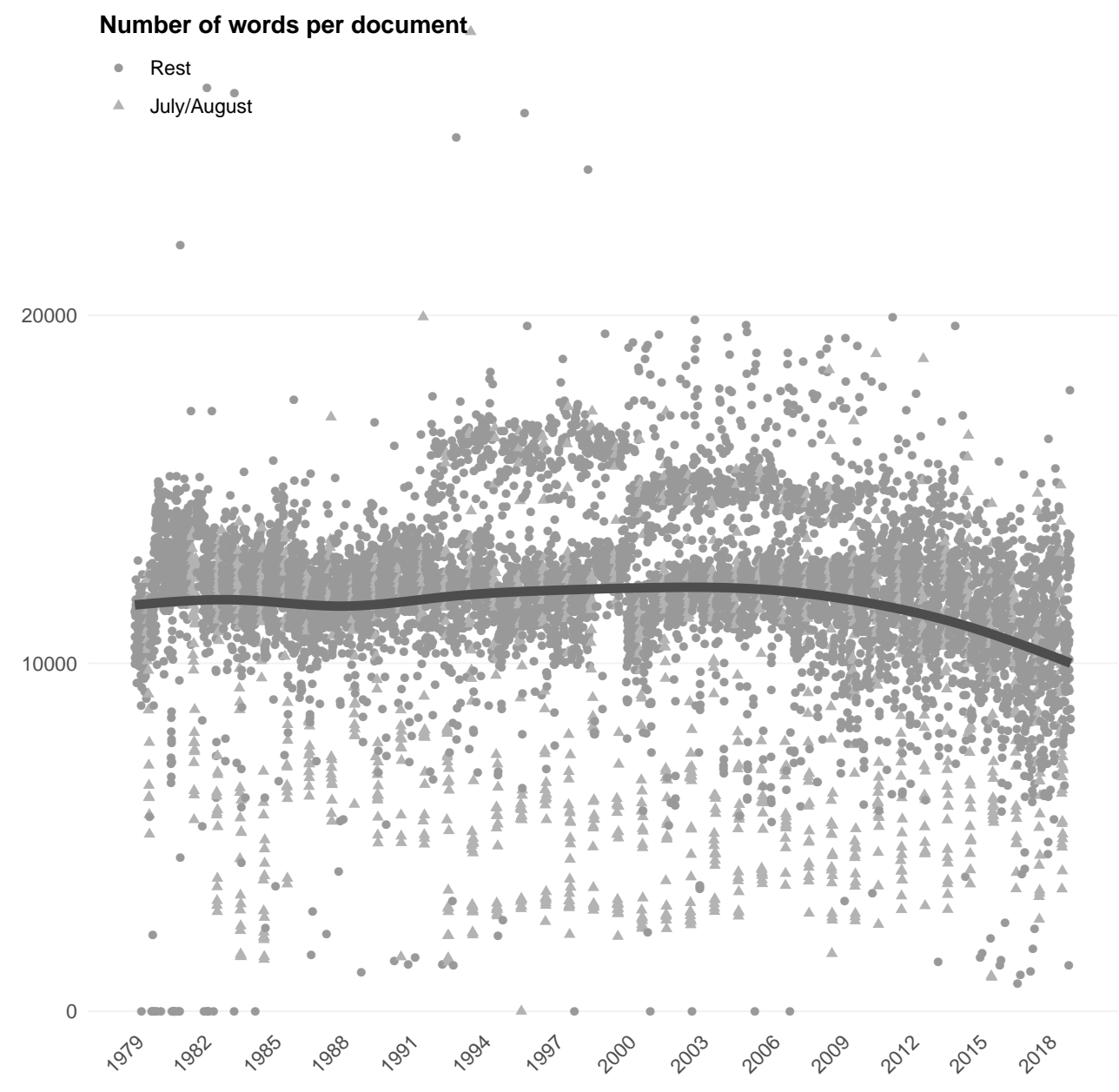

Figure 1: Number of words per document in the raw corpus.

Whereas document length is relatively consistent around the period corresponding to the transition from the scanned to the HTML format $(1999 / 2000)$, we can see a gradual decline since 2006. We speculate that this reflects editorial decisions driven by readership preferences as a consequence of the changing competitive landscape in the EU-level news market. That said, document length is on the whole remarkably stable, with outliers few and far between Systematic variation can be observed when comparing summer issues (in particular August) with the rest of the year, which mirrors the lighter workload of EU institutions and the less intense news cycle in this period (see also Figure 9 in Appendix).

\subsection{Pre-processing}

As is customary for text-mining applications, our pre-processing steps involve removing white-spaces, punctuation, numbers and stop-words together with stemming, while

\footnotetext{
${ }^{8}$ Sentence and character-level measures produce results very similar to the word-level measure. We report the latter because words constitute the unit of analysis in the topic model.
} 
converting all characters to lower case. The goal of pre-processing is to strike the right balance between reducing the inherent complexity of textual data and preventing the loss of relevant information (Denny and Spirling, 2018; Grimmer, 2010, Lucas et al. 2015). More specifically, Figure 2 illustrates our pre-processing strategy, which breaks down into three main steps: data collection, cleaning and reduction. As half of our data consists of scanned documents, we attempted to minimize unwanted distortions in the data collection phase by applying a state-of-the-art optical character recognition (OCR) technique which improves the likelihood of successful text extraction (Smith, 2007). Using recognized words as training data, the OCR algorithm detects the individual component features from which a character is made.

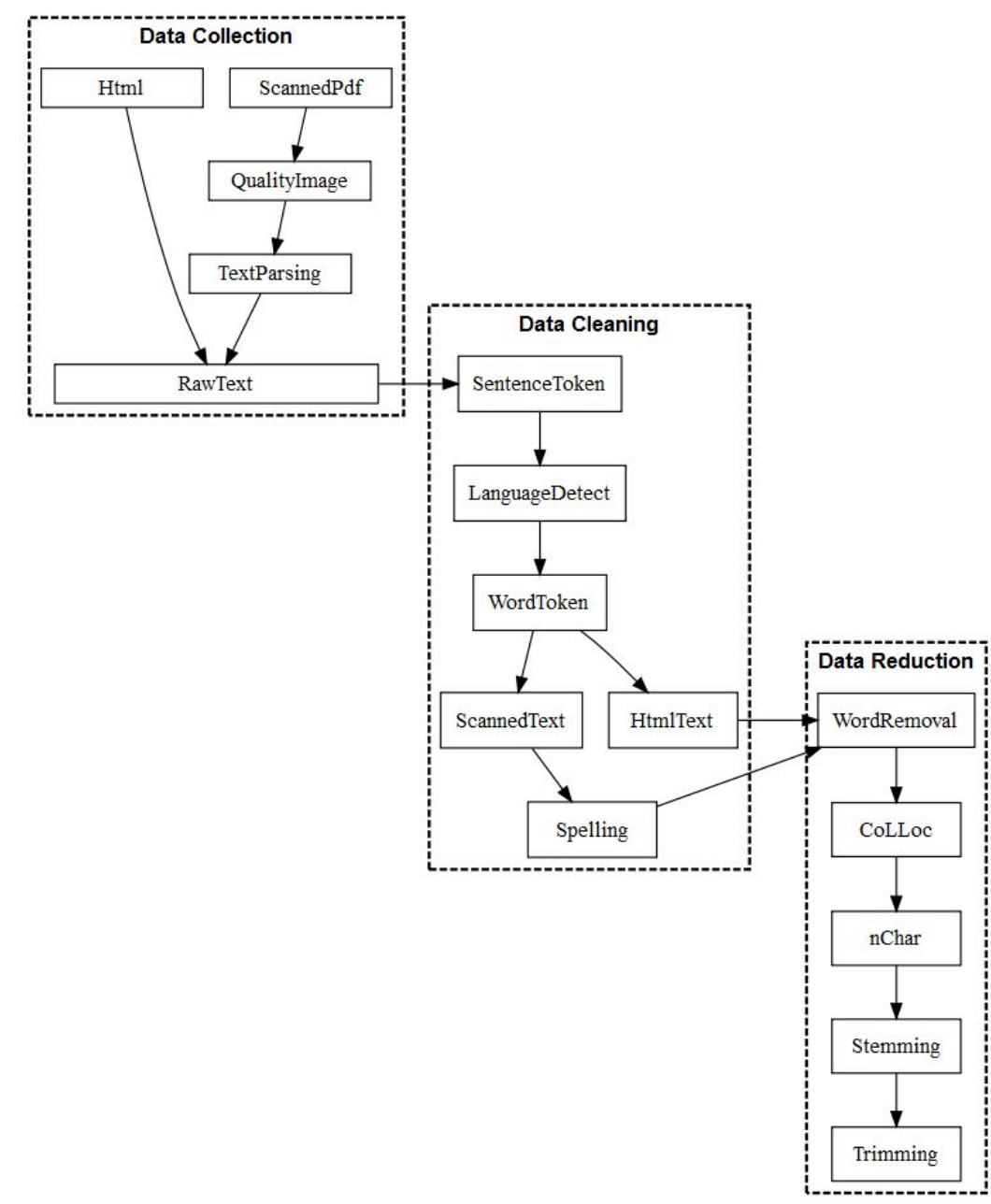

Figure 2: Data pre-processing steps.

The second stage of pre-processing involves the removal of undesirable documentspecific (quasi-)words. A substantial number of bulletins feature sentences or paragraphs written in a language other than English (often French). In order to avoid misclassification problems in the topic model, we tokenize all documents at the sentence 
level and apply a language detection tool to identify non-English sentences, which we then remove from the corpus. Owing to frequent misspelling, typos and similar errors resulting from either incorrect character recognition or the original texts, we employ a dictionary-based spell-checker after tokenizing the sentences at the word level Ooms, 2017). Erroneous terms are replaced by most likely suggested words or dropped if no suggestion is available, as is the case for garbage tokens. In the last step we apply four common pre-processing techniques $9^{9}$ aiming at reducing the number of features in the final document-term matrix: removal of uninformative word $\$ 10$ and terms shorter than three or longer than fifteen characters, reducing words to their stem (stemming), and dropping words appearing in more than $95 \%$ and fewer than $5 \%$ of all documents. During this stage we also convert frequent - appearing at least 1000 times in the corpus - two-word collocations (bi-grams) into single expressions (for example, "cohesion" followed by "policy" becomes "cohesion_polici").

While the present paper emphasizes our own indicator, which, we are confident, should meet the needs of many researchers in search of generic EU-level measure of issue attention, the textual corpus enables the construction of alternative indicators, a different set of techniques (e.g. supervised classification, vector embeddings) and/or choosing distinct units of time (week, month) or level of generality. All the data we collected and generated - whether the raw and pre-processed corpus or the final EUSSUE indicator - are available on masked for review for researchers to use.

\subsection{Dynamic Topic Modelling and Human Classification}

With individual bulletins spanning around 13,000 words on average, coding our corpus manually would require an impossibly large amount of resources. For that reason, we rely on automated content analysis techniques to estimate the latent topical structure of our corpus Quinn et al., 2010, Grimmer and Stewart, 2013, Grimmer, 2010, Kim, 2018; Dybowski and Adämmer, 2018; Rothschild et al., 2019, Catalinac, 2016). Developments in machine learning and natural language processing have led to the emergence of probabilistic topic modelling as a powerful technique to classify large collections of documents (Blei et al., 2003; Blei and Lafferty, 2006). Originally developed by (Blei et al., 2003), Latent Dirichlet Allocation (LDA) remains the most popular topic modelling approach. Yet increasingly sophisticated or specialized topic modelling algorithms have appeared in recent years ranging from non-negative matrix factorization to hierarchical topic models (Greene and Cross, 2017; Blei, 2012; Grimmer, 2010; Rosen-Zvi et al., 2004). All topic models, though, share the same basic assumptions. While reducing texts to bags of words, they model topics as latent prob-

\footnotetext{
${ }^{9}$ See the Appendix for a comparison with an alternative pre-processing strategy.

${ }^{10}$ Custom words removed are listed in the Appendix.
} 
ability distributions over words and documents as latent probability distributions over topics.

Although LDA - the plain vanilla approach to topic modelling - is a powerful algorithm for analysing large corpora, it is not well-suited for dynamic corpora, where topics may change over time. Dynamic topic modelling addresses this problem by extending the idea of LDA to allow topic representation to evolve over fixed time intervals (Blei and Lafferty, 2006). The multi-purpose structural topic model developed by Roberts et al. (2014) and implemented in the stm package for $\mathrm{R}$ allows the estimation of a topic model where each topic is represented not by a single distribution over words but, instead, by a sequence of distributions over the time intervals. Building on the Correlated Topic Model (Blei et al., 2007), the stm implementation assumes a logistic normal generalized linear model instead of a latent dirichlet process for topic proportion (Roberts et al., 2014). Here we choose the year as time interval, as it is a common unit of time to track agenda formation dynamics.

Formally, our time interval enters the document-generating process as a covariate interacting with topic prevalence:

$$
\theta_{1: D} \mid t_{1: D} \gamma, \Sigma \sim \operatorname{LogisticNormal}\left(\mu=t_{1: D} \gamma, \Sigma\right) \text {. }
$$

where $t_{d}$ is the year in which document $d$ was published; $\gamma$ is a $p \times(K-1)$ matrix of coefficients for topic proportion and $\Sigma$ is a $(K-1) \times(K-1)$ covariance matrix. A topic $z$ is drawn from the document specific distribution, conditional on that topic $k$, a word is chosen from the multinomial distribution over words denoted by $\beta_{d, k}$ :

$$
\beta_{d, k} \quad \infty \quad \exp \left(m+\kappa_{k}\right)
$$

where $m$ represents the baseline word frequencies and $\kappa_{k}$ the topic deviation per topic $k$. Conditional on the topic selected and token-level distribution $z_{d, n}$ where $n \in[1, \ldots, N-d]$ for each word in the document, the observed word $w_{d, n}$ is drawn from a multinomial distribution:

$$
w_{d, n} \mid z_{d, n}, \beta_{d, k=z_{d, k}} \sim \operatorname{Multinomial}\left(\beta_{d, k=z_{d, k}}\right)
$$

As implemented in the stm package, the posterior distribution for this dynamic topic model is computed via variational expectation maximization (Roberts et al. 2019). The number of topics $k$ in a topic model is set by the researcher and determines the dimension of the topic space. A larger $k$ provides a more detailed picture of the corpus, while a smaller $k$ results in a simpler, more general picture. A variety of metrics, such as harmonic mean, perplexity, log-likelihood, semantic exclusivity and coherence, have been proposed to evaluate the quality of the model and to choose 
the number of topics (Wallach et al., 2009; Chang et al., 2009, Mimno et al., 2011). However, there is no "right" $k$ and the validity of these formal criteria is not well established; perplexity, for one, has been shown to be inversely correlated with human interpretability (Chang et al., 2009). For our main analysis, we ignore these formal metrics. Instead, we set the number of topics on the basis of two criteria. The first is interpretability. There is little point in using topic modelling if the resulting topics, or at least a large number of them, eschew human interpretation. The second criterion is motivated by the aim of our classification exercise: we want a sufficiently large number of topics to provide a relatively fine-grained picture of agenda variation. After iterating several topic models, we settled on $k=88$ as providing a sufficiently large number of interpretable topics. We found that a higher $k$ produces few additional meaningful topics, whereas a lower $k$, though producing interpretable topics, offers a less detailed picture 11

Using unsupervised document classification to construct a measure of issue attention has advantages as well as drawbacks. Topic modelling is an inductive, data-driven approach. Whereas supervised classification and manual coding schemes presuppose that the researcher knows the relevant categorizations a priori Alexandrova et al., 2014), topic modelling lets the data speak first. The topics do not come from the researcher's a priori definition but emerge from the data. Thus a topic model may reveal issues the researcher had not thought of. However, to the extent that one has a priori knowledge of the items that a measure of issue salience should include or wishes to relate the results to other, human-coded indicators, the topic model may fail to capture the categories of interest to the researcher. Our approach mitigates this problem by adding a layer of human coding to the topic model. We organize the machinegenerated topics into more general themes. For this, we follow the coding scheme of the EU Policy Agendas Project (Alexandrova et al., 2014), from which we only deviate with respect to the European Parliament, the Eurozone and EU Treaties. ${ }^{12}$ This makes our measure easier to relate to existing EU-level indicators.

\footnotetext{
${ }^{11}$ Figure 15 in the Appendix evaluates the model performance at varying number of topics.

${ }^{12}$ The deviation rests in the fact that we code these three issues at the theme level rather than as part of the "EU Governance" theme. The issues receive sufficient attention in the AEB to warrant this more granular approach compared to the EU Policy Agendas project. If complete comparability is desired, these additional themes can be collapsed by researchers into the "EU Governance" theme.
} 


\section{EUSSUE: A Generic, EU-Level Measure of Issue Attention}

Similarly to Quinn et al. (2010), we aim to construct a classification scheme with items that sustain attention over time. We take this to imply that topics must transcend mere events. Nevertheless, as will be seen below, our classification method identifies considerable temporal variation in topic proportion.

The most important output of our dynamic topic model is the topic proportion per document $\theta$. We interpret this value as a measure of issue attention in the $k$ dimensional topic space. For topic $i$ at time $t$, a larger $\theta_{i t}$ indicates greater topic prevalence. Ignoring the temporal dimension for the moment, Table 1 shows the topic proportions for all 88 topics in our model. The table includes also the words most distinctive of each topic, as determined by the word-level parameter $\beta$. 
Table 1: Topic Proportions and Top Words for 88-Topic Model

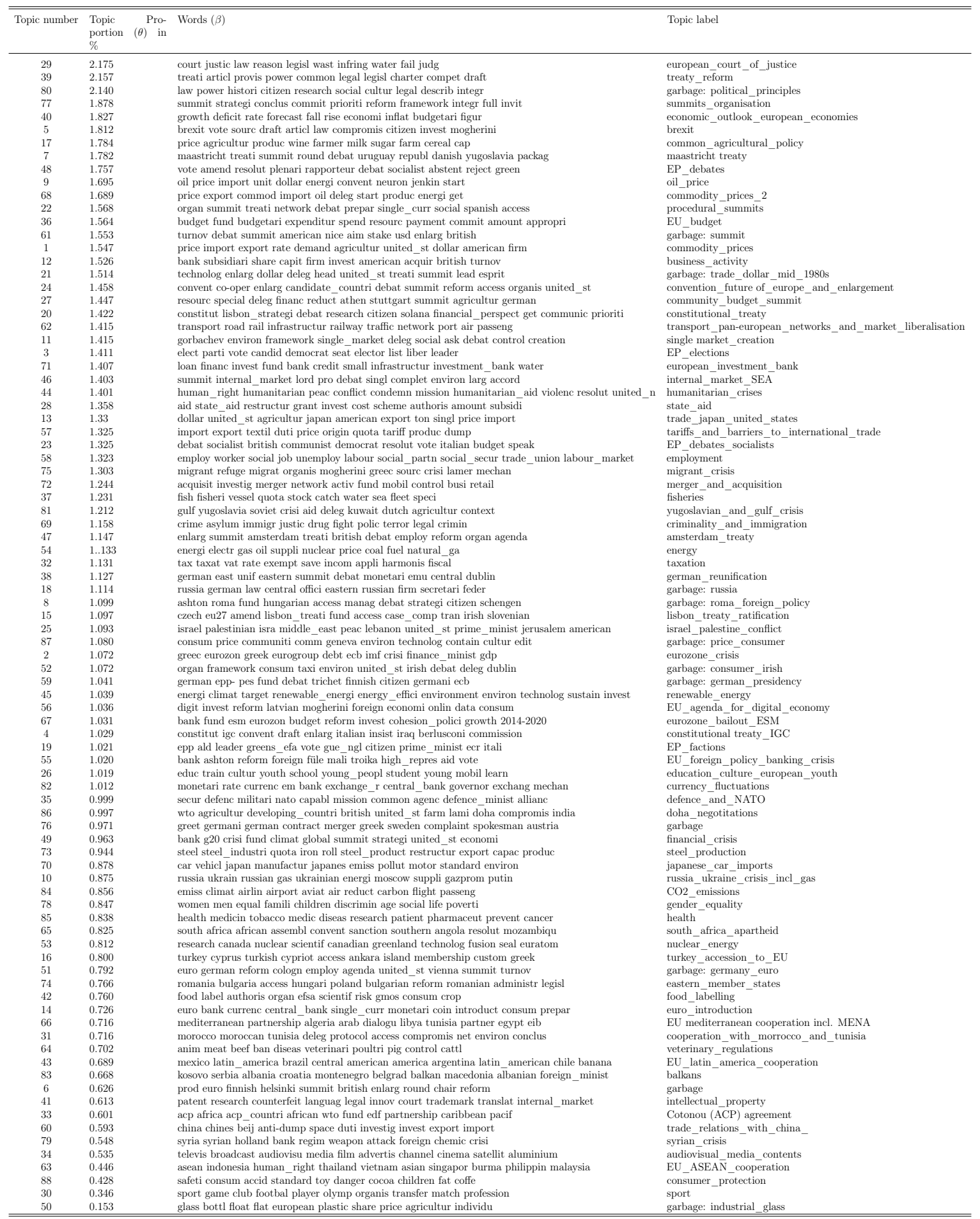

In the next step we proceeded to label all topics and identify those which are not useful for our measurement objectives. The topics were labelled independently by two of the authors with the third one reconciling discrepancies 13 The labels were assigned

${ }^{13}$ We use the average cosine similarity to measure inter-coder reliability for topic labelling yielding 0.761. The correlation of assigning the themes of the Policy Agenda project is 0.878 . 
on the basis of the topic's most distinctive words (based on $\beta$ value), most distinctive documents (based on $\theta$ value) and varying proportion over time. As is common in unsupervised document classification, some topics proved, despite the care we put in selecting the model, impossible to interpret. While "garbage" topics may take up a significant proportion of the topic space (Quinn et al., 2010), in our case this amounts to a tolerable $13.2 \%$ of the total. We discarded these topics, thereby bringing the number of topics down to 75 14

As can be readily seen in Table 1, several topics relate to a similar overarching theme such as agriculture or the euro. As explained above, we organized the topics into 19 themes following a coding scheme largely inspired by the EU Policy Agendas Project.

\footnotetext{
${ }^{14}$ This step also involved merging two topics dealing with commodity prices into one after adjudging that they captured the same issue.
} 
Table 2: EUSSUE Topics Clustered into Themes

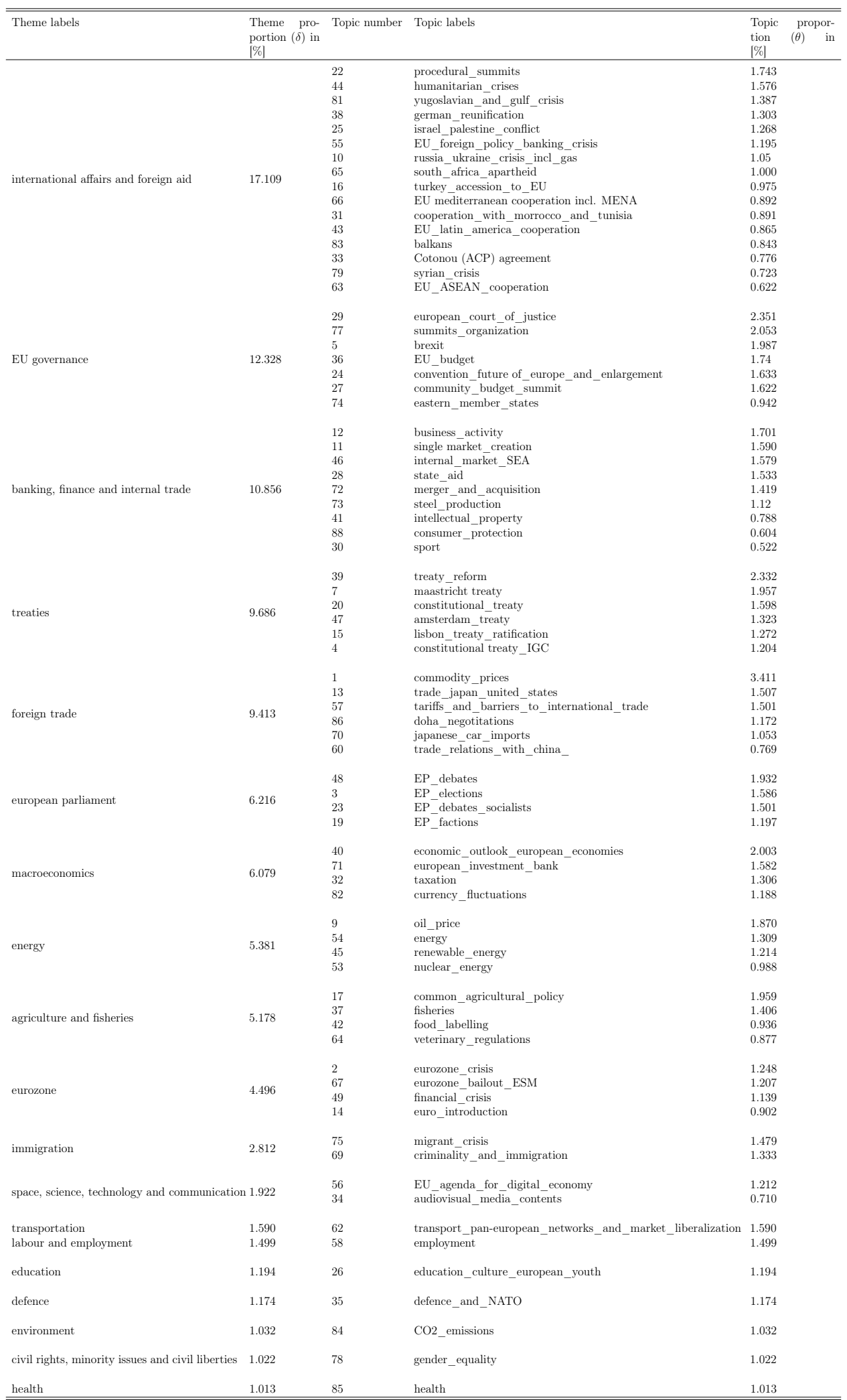

This task was completed following the same procedure as topic labelling, with two researchers annotating topics independently and a third one reconciling the discrepan- 
cies.15 We call the resulting generic, EU-level measure of issue attention "EUSSUE". Table 2 shows the labelled topics and themes with the attached (overall) proportions.

Figure 3 illustrates how issue attention varies over time using the theme level of analysis. Among other things, the plot suggests a decline in the salience of foreign trade but a surge in the salience of immigration around 2015, while agriculture exhibits remarkable stability: ${ }^{16}$

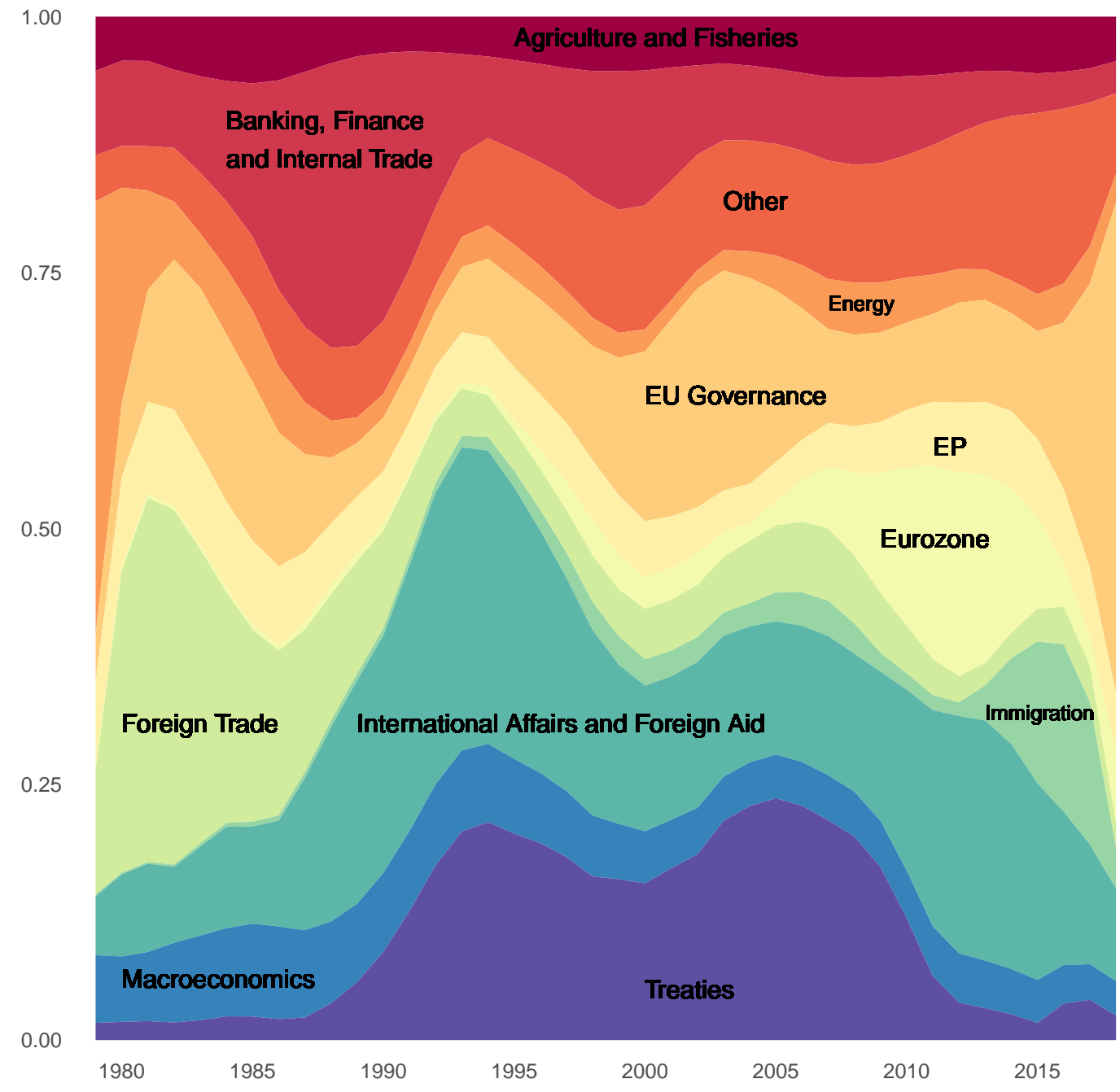

Figure 3: EUSSUE theme-proportion over time

Note. The theme "Other" comprises the seven smallest themes in terms of proportion for the sake of visualization. With the exception of themes "European Parliament", "Eurozone" and "EU Treaties", thematic clustering is aligned with the codebook of the Agendas Project (Alexandrova et al. 2014).

${ }^{15}$ Results based on more formal clustering metrics are reported in the Appendix.

${ }^{16}$ The data can be explored online at https://eussue.shinyapps.io/eussue_shiny/ 


\section{Validation}

Because our classification scheme is, for the largest part, machine-generated, it requires validation (Grimmer and Stewart, 2013). Both the nature of the documents and the relative complexity of our classification scheme presented a validation challenge. The bulletins are lengthy and varied documents, issued in changing economic and geopolitical contexts. Also, because our unsupervised content analysis method models documents as mixtures of topics, a document is assumed to feature all topics, although in proportion varying from large to infinitesimally small. As a consequence, we had reasons to expect that human coders would, at times, lack the historical knowledge or expertise to situate the events described in the bulletins and relate them to the correct topic in our classification scheme. Still, we opted for a simple, conservative validation procedure. We took a random sample of bulletins and then independently asked untrained coders to determine which of the 75 EUSSUE topics they believed to be instantiated in these documents. Each coder had first to read the document and then tick a box in a form listing the 75 topics. The exercise spanned 20 unique documents, for a total of 49 coder-document observations.

Inter-coder reliability was 56 per cent, which is reasonably high for a validation task of such complexity (Hruschka et al. 2004). It bears emphasis, in particular, that, owing to the high number of topics, the probability that coders would agree simply by chance was very small. Cohen's $\kappa$, which this probability into account, averages 0.53 across pairwise coder comparisons.

To evaluate how our computer-based measure of topic proportion compares to human coding, we related the documents' $\theta$ values from the topic model to the coders' determination regarding the presence of the corresponding topics. Whether we regress human coding on $\theta$ (using logistic regression) or $\theta$ on the coders' choice (using OLS regression), we find a positive and strongly significant association, as shown in Table 3 , 
Table 3: Relationship between EUSSUE $\theta$ and manual coding of a random sample of Agence Europe bulletins.

\begin{tabular}{|c|c|c|c|c|}
\hline & \multicolumn{4}{|c|}{ Dependent variable: } \\
\hline & Coders' Choice & $\theta$ & Coders' Choice & $\theta$ \\
\hline Constant & $\begin{array}{c}0.259^{* * *} \\
(0.053)\end{array}$ & $\begin{array}{l}0.010^{* *} \\
(0.005)\end{array}$ & $\begin{array}{c}0.221^{* * *} \\
(0.007)\end{array}$ & $\begin{array}{l}0.011^{* * *} \\
(0.0005)\end{array}$ \\
\hline$\theta$ & $\begin{array}{c}1.856^{* * *} \\
(0.221)\end{array}$ & & $\begin{array}{c}1.856^{* * *} \\
(0.219)\end{array}$ & \\
\hline Coder's Choice & & $\begin{array}{c}0.012^{* * *} \\
(0.002)\end{array}$ & & $\begin{array}{c}0.011^{* * *} \\
(0.002)\end{array}$ \\
\hline FE Author & Yes & Yes & No & No \\
\hline FE Bulletin & Yes & Yes & No & No \\
\hline Observations & 3,825 & 3,825 & 3,825 & 3,825 \\
\hline $\mathrm{R}^{2}$ & & 0.021 & & 0.021 \\
\hline Adjusted $\mathrm{R}^{2}$ & & 0.014 & & 0.021 \\
\hline McFadden Pseudo $\mathrm{R}^{2}$ & 0.038 & & 0.018 & \\
\hline Log Likelihood & $-2,123.067$ & & $-2,165.995$ & \\
\hline Akaike Inf. Crit. & $4,308.134$ & & $4,335.991$ & \\
\hline Residual Std. Error & & $0.033(\mathrm{df}=3794)$ & & $0.033(\mathrm{df}=3823)$ \\
\hline F Statistic & & $2.758^{* * *}(\mathrm{df}=30 ; 3794)$ & & $81.532^{* * *}(\mathrm{df}=1 ; 3823)$ \\
\hline
\end{tabular}

Note. ${ }^{*} \mathrm{p}<0.1 ;{ }^{* *} \mathrm{p}<0.05 ;{ }^{* * *} \mathrm{p}<0.01$

Robust standard errors are given in parentheses.

Table 4 further reports the degree of agreement between human coders and our 19 theme-level categories. Correlation coefficients are mostly positive and often significant. Moreover, even if we group the data at the theme level, we observe consistently high correlation across all themes (see 7 in the Appendix). These results, we believe, support the validity of our measurement method. 
Table 4: Correlation between EUSSUE theme proportions and human coding at bulletin level

\begin{tabular}{|c|c|c|c|}
\hline & Pearson & Spearman & Number of coders \\
\hline BNo_04921 & $\begin{array}{c}0.849^{* * *} \\
(0.849 ; 0.849)\end{array}$ & $\begin{array}{c}0.738^{* * *} \\
(0.738 ; 0.738)\end{array}$ & 5 \\
\hline BNo_10929 & $\begin{array}{c}0.837^{* * *} \\
(0.837 ; 0.837)\end{array}$ & $\begin{array}{c}0.586^{* * *} \\
(0.153 ; 1.019)\end{array}$ & 5 \\
\hline BNo_11656 & $\begin{array}{c}0.641^{* * *} \\
(0.218 ; 1.064) \\
\end{array}$ & $\begin{array}{c}0.338 \\
(-0.13 ; 0.806)\end{array}$ & 5 \\
\hline BNo_02687 & $\begin{array}{c}0.562^{* *} \\
(0.123 ; 1.001)\end{array}$ & $\begin{array}{c}0.441^{*} \\
(-0.018 ; 0.900)\end{array}$ & 2 \\
\hline BNo_02720 & $\begin{array}{c}0.501^{* *} \\
(0.051 ; 0.951)\end{array}$ & $\begin{array}{c}0.820^{* * *} \\
(0.820 ; 0.820)\end{array}$ & 2 \\
\hline BNo_03257 & $\begin{array}{c}0.546^{* *} \\
(0.101 ; 0.991)\end{array}$ & $\begin{array}{c}0.818^{* * *} \\
(0.818 ; 0.818)\end{array}$ & 2 \\
\hline BNo_04900 & $\begin{array}{c}0.815^{* * *} \\
(0.815 ; 0.815)\end{array}$ & $\begin{array}{c}0.416^{*} \\
(-0.046 ; 0.878)\end{array}$ & 2 \\
\hline BNo_05078 & $\begin{array}{c}0.592^{* * *} \\
(0.155 ; 1.029)\end{array}$ & $\begin{array}{c}0.468^{* *} \\
(0.014 ; 0.922)\end{array}$ & 2 \\
\hline BNo_05151 & $\begin{array}{c}0.577^{* * *} \\
(0.138 ; 1.016)\end{array}$ & $\begin{array}{c}0.625^{* * *} \\
(0.200 ; 1.050)\end{array}$ & 2 \\
\hline BNo_05231 & $\begin{array}{c}0.641^{* * *} \\
(0.218 ; 1.064)\end{array}$ & $\begin{array}{c}0.320 \\
(-0.148 ; 0.788)\end{array}$ & 2 \\
\hline BNo_05361 & $\begin{array}{c}0.452^{*} \\
(-0.005 ; 0.909)\end{array}$ & $\begin{array}{c}0.273 \\
(-0.198 ; 0.744)\end{array}$ & 2 \\
\hline BNo_05541 & $\begin{array}{c}0.664^{* * *} \\
(0.244 ; 1.084)\end{array}$ & $\begin{array}{c}0.576^{* * *} \\
(0.138 ; 1.014)\end{array}$ & 2 \\
\hline BNo_06710 & $\begin{array}{c}0.625^{* * *} \\
(0.200 ; 1.050)\end{array}$ & $\begin{array}{c}0.690^{* * *} \\
(0.281 ; 1.099)\end{array}$ & 2 \\
\hline BNo_07664 & $\begin{array}{c}0.643^{* * *} \\
(0.219 ; 1.067)\end{array}$ & $\begin{array}{c}0.362 \\
(-0.104 ; 0.828)\end{array}$ & 2 \\
\hline BNo_09499 & $\begin{array}{c}0.371 \\
(-0.094 ; 0.836)\end{array}$ & $\begin{array}{c}0.609^{* * *} \\
(0.175 ; 1.043)\end{array}$ & 2 \\
\hline BNo_10072 & $\begin{array}{c}0.297 \\
(-0.174 ; 0.768)\end{array}$ & $\begin{array}{c}0.343 \\
(-0.124 ; 0.810)\end{array}$ & 2 \\
\hline BNo_10185 & $\begin{array}{c}0.282 \\
(-0.189 ; 0.753)\end{array}$ & $\begin{array}{c}0.403 \\
(-0.059 ; 0.865)\end{array}$ & 2 \\
\hline BNo_10331 & $\begin{array}{c}0.180 \\
(-0.289 ; 0.649)\end{array}$ & $\begin{array}{c}0.125 \\
(-0.338 ; 0.588)\end{array}$ & 2 \\
\hline BNo_10858 & $\begin{array}{c}0.330 \\
(-0.137 ; 0.797)\end{array}$ & $\begin{array}{c}0.448^{*} \\
(-0.01 ; 0.906)\end{array}$ & 2 \\
\hline BNo_11713 & $\begin{array}{c}0.328 \\
(-0.14 ; 0.796)\end{array}$ & $\begin{array}{c}0.187 \\
(-0.283 ; 0.657)\end{array}$ & 2 \\
\hline
\end{tabular}

Note. A random sample of Agence Europe bulletins has been selected for the validation.

\section{Relation to European Council Agenda Items}

While manual topic validation demonstrates that our method is effective at extracting agenda items from the AEB documents, comparing EUSSUE with an existing measure of EU agenda formation is useful to understand how a generic indicator differs from actor-centred ones. The European Union Policy Agendas Project offers the only quantitative measure comparable to the EUSSUE measure proposed here (Alexandrova et al., 2014). As highlighted above, EUSSUE and the Agendas Project differ in two important respects. First, one is based on European Council conclusions, which are essentially outcomes of political negotiations, whereas the other is built on journalistic 
reporting. Second, the two measures also diverge in the way they capture the time dimension. AEB is published on average five times a week, while European Council summits have traditionally had biannual recurrence. In sum, the two indicators are designed to measure different things. So, while a degree of overlap is to be expected - European Council conclusions are normally reported in the AEB - they should also exhibit a fair amount of divergence.

Generally speaking, our measure attributes greater saliency to items relating to EU institutions (notably European Parliament debates), the Eurozone and EU Treaties than the European Council conclusions coded in the Agendas Project. This is the reason why we created specific themes for these items, thereby deviating from the meta-classification employed in the Agendas Project. For the purpose of comparing the EUSSUE with the Agendas Project, we collapse the Eurozone topic under "macroeconomics" and European Parliament and EU Treaties under "EU governance". For each theme we computed the annual theme proportion for the period 1979-2014 shared by both indicators. ${ }^{17}$ Figure 4 shows the correlations between the two measures with data aggregated by theme and year. Because the data is a mixture of normal and skewed distributions, we report three correlation methods. Coefficients are $\bar{r}=0.28 ; \bar{\rho}=0.24 ; \bar{\tau}=0.17$ for, respectively, Pearson, Spearman and Kendall correlation.

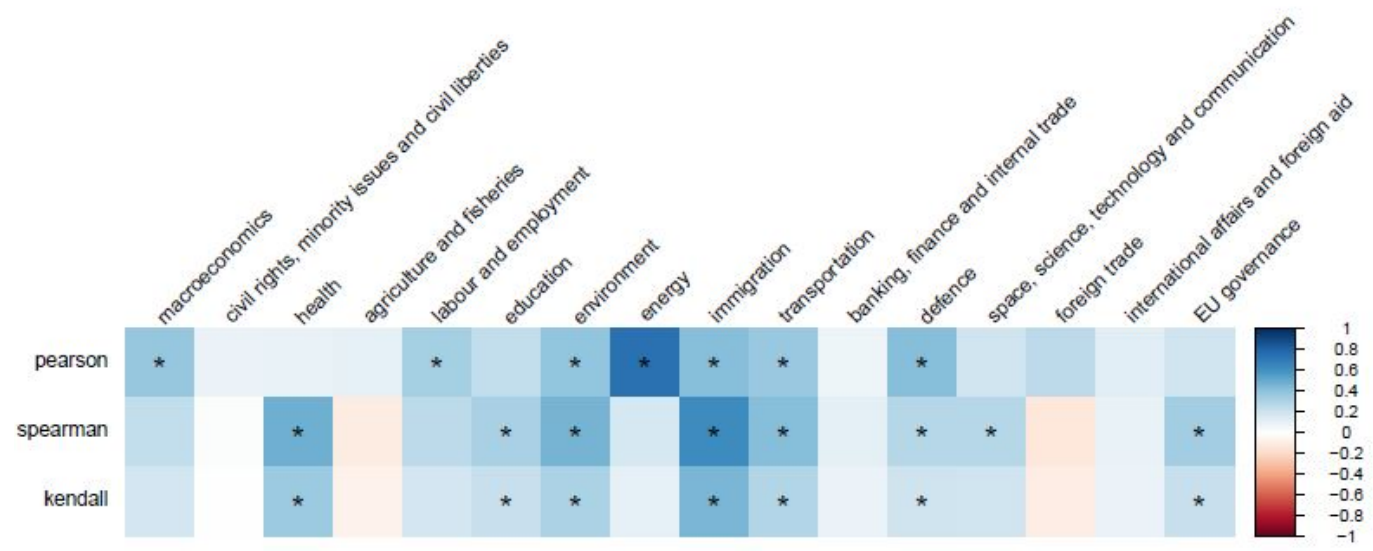

Figure 4: Pearson's, Spearman's and Kendall's correlation between paired theme-year observations in the EUSSUE and Agenda Project datasets. Asterisk denotes statistical significance at $p-$ value $<0.05$.

Given the underlying differences in measurement design and approach, it should not come as a surprise that the correlations oscillate, for the most part, between low and medium. It is also understandable that rank correlation is overall lower than

\footnotetext{
${ }^{17}$ We add zeros to the Agendas Project data for years where no sentence is coded as belonging to a given topic and convert the counts into proportions, taking into account the length of European Council conclusions in each year.
} 
linear correlation, since issue attention frequently surges considerably in response to crises with the scale of such a phenomenon co-occurring in both measures captured to a larger extent by a linear function. The greatest difference between linear and rank correlation can be seen for theme "energy" ( $r=0.75 ; \rho=0.18 ; \tau=0.10)$. A visual inspection of the data (see Figure 5) demonstrates that both measures share important similarities, in particular for the period of the 1979 oil crisis and in the mid 2000s. Themes which consist of merely one topic - such as health, civil rights, space and science - in the EUSSUE measure tend to be weakly correlated with the corresponding items in the Agendas Projects. Also, whereas agriculture seems to enjoy sustained saliency in AEB, it is much less present in European Council conclusions, which may reflect the fact that this policy has been, in large measure, delegated to the European Commission (Alexandrova, 2017). Overall, these results are consistent with our expectation that while partly overlapping, EUSSUE and the Agendas Project represent distinct measures of issue attention.

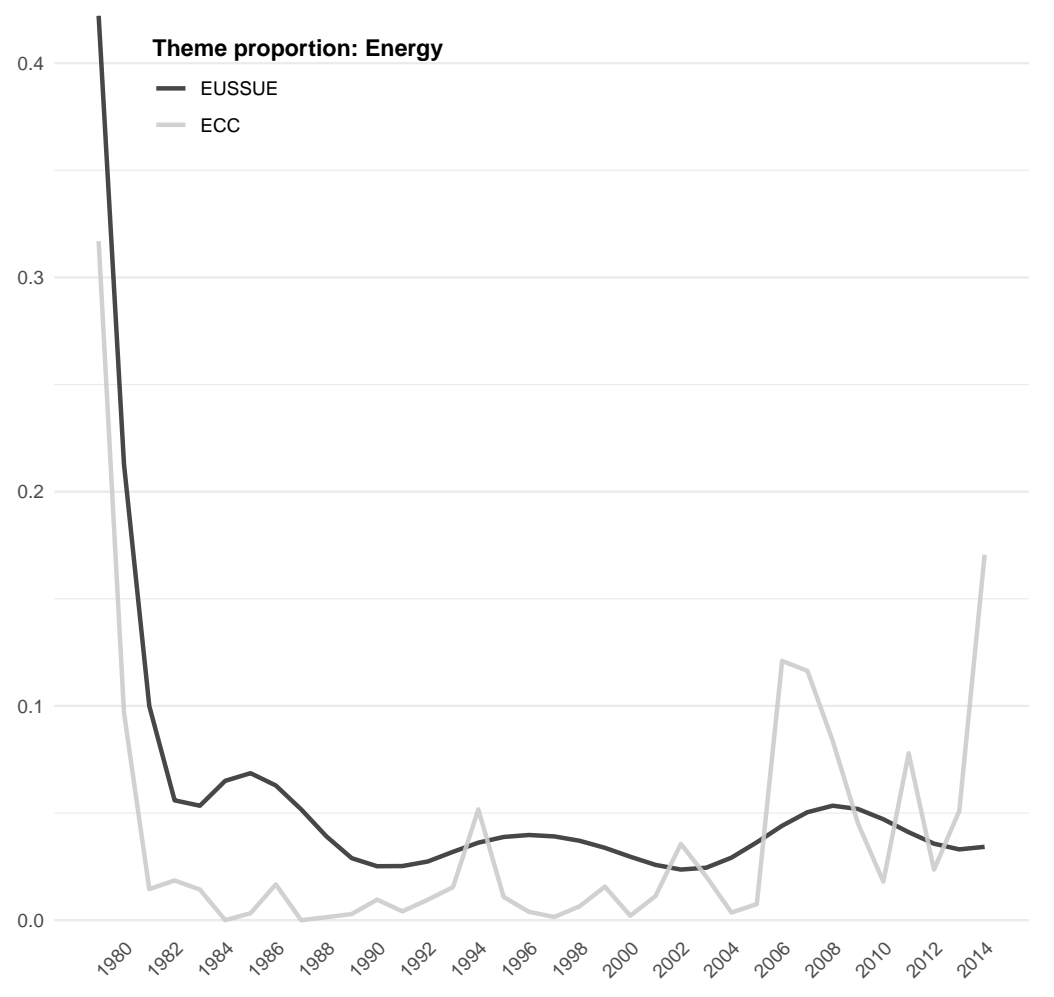

Figure 5: Comparison of EUSSUE and Agendas Project data on attention paid to theme "energy" between 1979 and 2014. 


\section{Events and Temporal Patterns}

Finally, we relate the EUSSUE to a selected set of exogenous events. While not strictly equivalent to a validation exercise, this helps shore up our assumption that AEB provides a generic and relatively neutral measure of issue attention. If this assumption is correct, then we should expect topic and theme proportion to correlate with major events, such as armed conflicts and economic crises, where these topics are central. Simultaneously, this exercise helps illustrate how our indicator can be used in research on EU affairs. As a first illustration, we consider the topic "CO2_emissions". At the most basic level we should expect this topic to reflect the rising political and social salience of climate questions since the 1980s and, more recently, the intense diplomatic efforts to bring countries together to cap and reduce greenhouse gases globally. Because the EU has been a key player in this international political effort, we expect the EUSSUE to reflect this. The sizeable literature on the EU's role in the international climate change regime highlights the 2009 Copenhagen summit as a salient juncture, exposing the failure of European leadership (Dimitrov, 2010, Haug and Berkhout, 2010; Oberthür, 2011; Groen and Niemann, 2013, Bäckstrand and Elgström, 2013). 


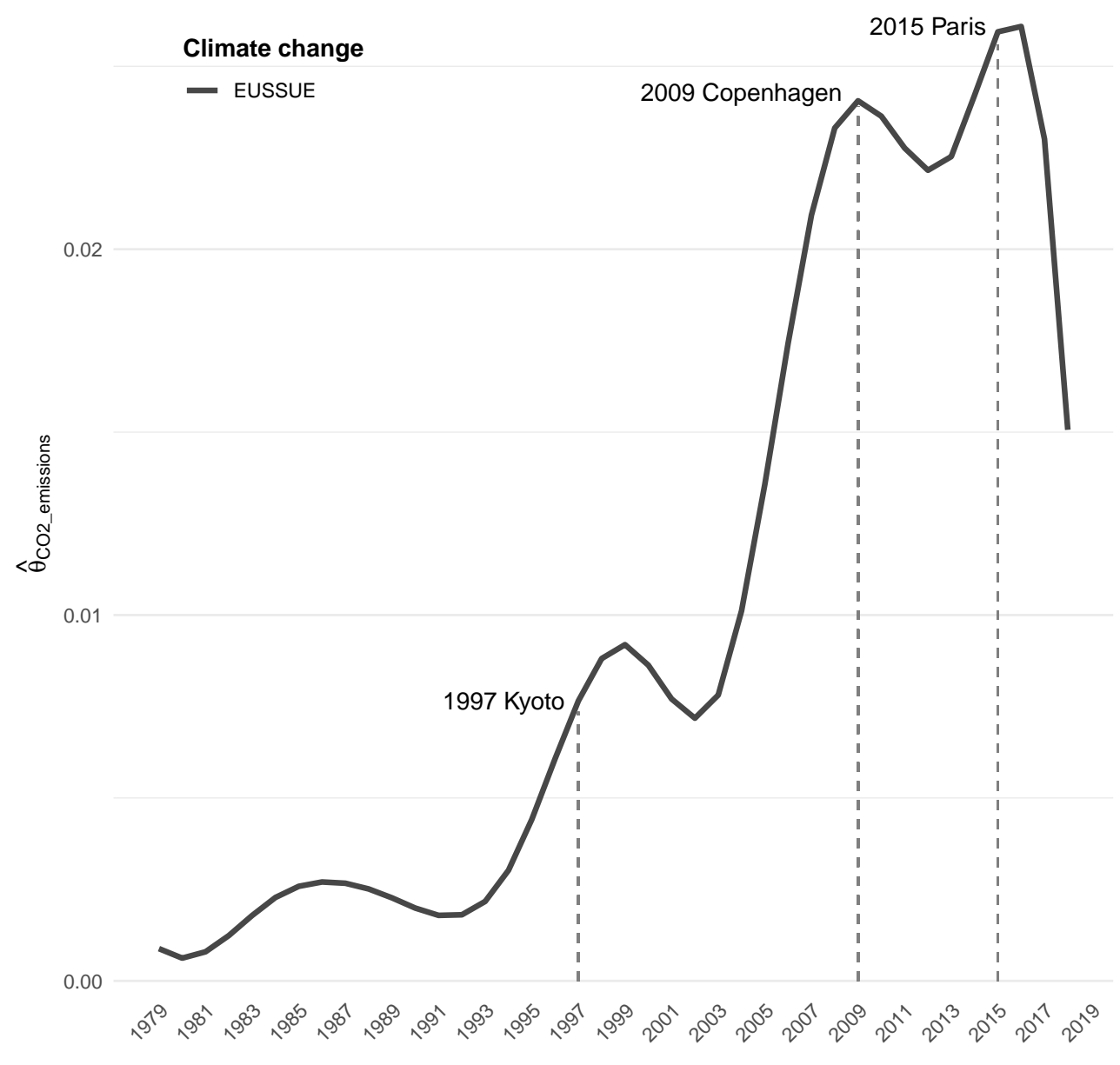

Figure 6: EUSSUE topic "CO2_emissions" and notable UN climate change summits.

In Figure 6 we can see that the 2009 Copenhagen summit coincides with one of the peaks of the "CO2_emissions" EUSSUE topic. The $\theta$ value for this topic, though, reaches its peak in 2016, which corresponds to the signature of the Paris Agreement. Our measure therefore behaves consistently with basic expectations about climate change issue attention in the EU: we observe decade-on-decade increases while peaks correspond to salient junctures.

The impact of climate change summits on issue attention can also be analysed at a more granular level using days rather than years as unit of time. Summits usually take place at the tail-end of calendar years and might otherwise go undetected when issue attention is aggregated at the year or semester level. Figure 7 reports the document-level $\theta$ of the "CO2_emissions" topic around the time of the 2009 Copenhagen summit.18

\footnotetext{
${ }^{18}$ In order to use document-level values we must remove the effect of the year-covariate present in the EUSSUE measure otherwise. This does not lead, however, to a large discrepancy. For the topic "CO2_emissions" the average effect is 0.00004 . Documents were annotated with their date of publication to construct the time-series.
} 


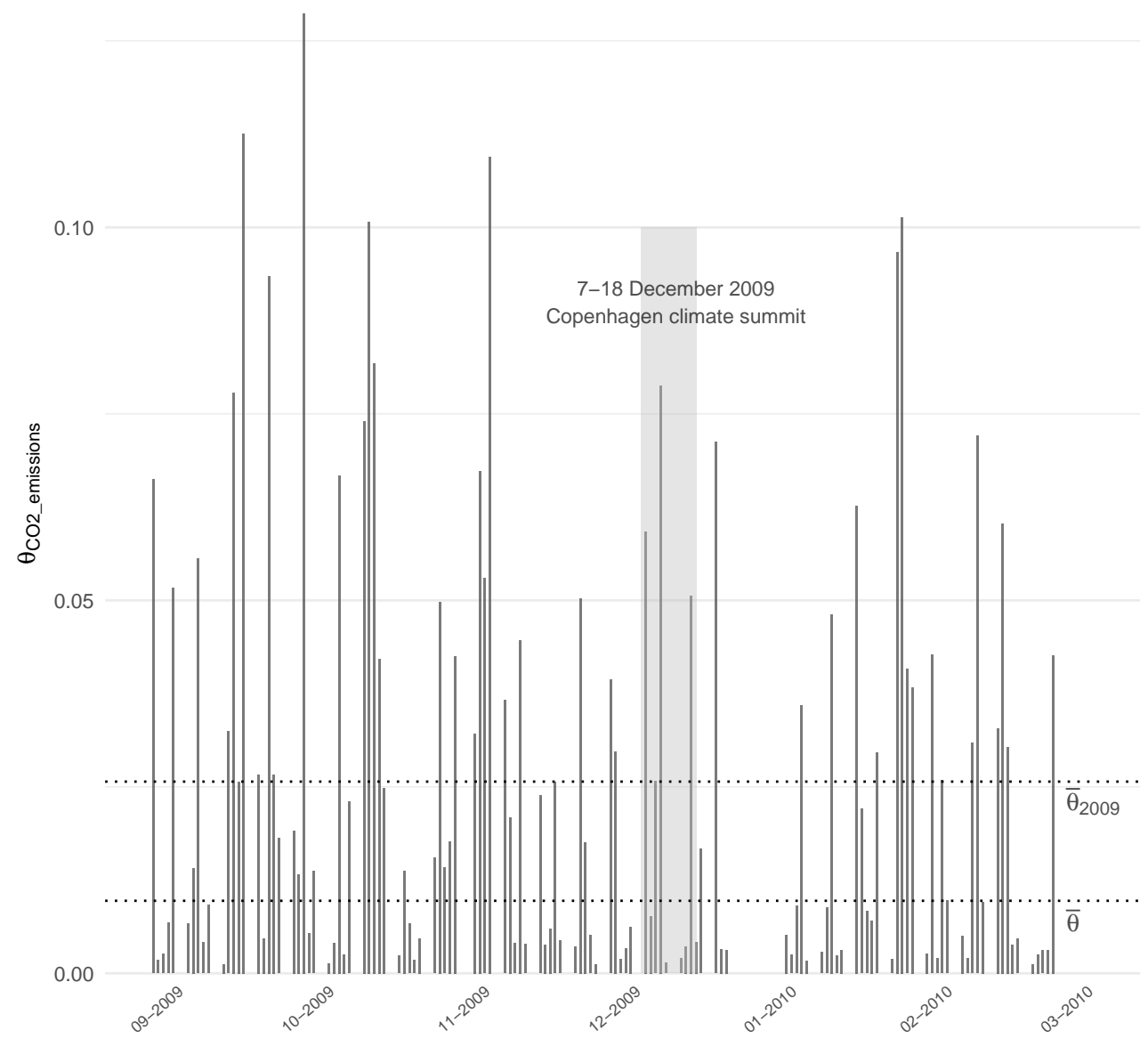

Figure 7: Document-level $\theta$ of EUSSUE topic "CO2_emissions" around the time of the 2009 Copenhagen climate change conference. The time-series window spans 1 September 2009 - 1 March 2010.

Figure 7 illustrates how the occurrence of significant events may affect issue coverage outside the strict window when they take place. This makes intuitive sense: in the case of a planned event such as the Copenhagen climate summit, actors prepare and can signal positions in the build-up to the event. The outcome of the event - failure of climate diplomacy and EU leadership - is subsequently discussed in its aftermath. As a result, the period around the Copenhagen summit has a higher $\bar{\theta}$ than the average for 2009, 2010 or overall.

Events and crises whose intensity can be credibly tracked using continuous indicators instead of individual time-moments provide another illustration of how AEB items respond to these events. Assuming again (imperfect) parallelism between issue attention and real-world developments intuitively recognized as economically or politically salient, we first use Greek bond yields as a proxy for the intensity of the Eurozone crisis. Bond yields capture a combination of risk factors which are sensitive to financial 
and sovereign debt conditions in a country (Manganelli and Wolswijk, 2009, Arghyrou and Kontonikas, 2012). As the situation in Greece was the most critical to the survival of the Eurozone during the European sovereign debt crisis, the country's bond yields summarize well the evolution of the crisis. Next, we consider the number of asylum applications as a proxy for the "European migrant crisis". While asylum-seekers are only one group of migrants, they were at the centre of the European migrant crisis when Germany opened its borders to Syrian refugees in 2015. Last, the Syria conflict is itself the subject of one of our EUSSUE topics. Here for the comparison with issue attention in the EU we take battle-related deaths as a relatively objective measure of the conflict's intensity. The association between these proxies and topics is depicted in Figure 8. 


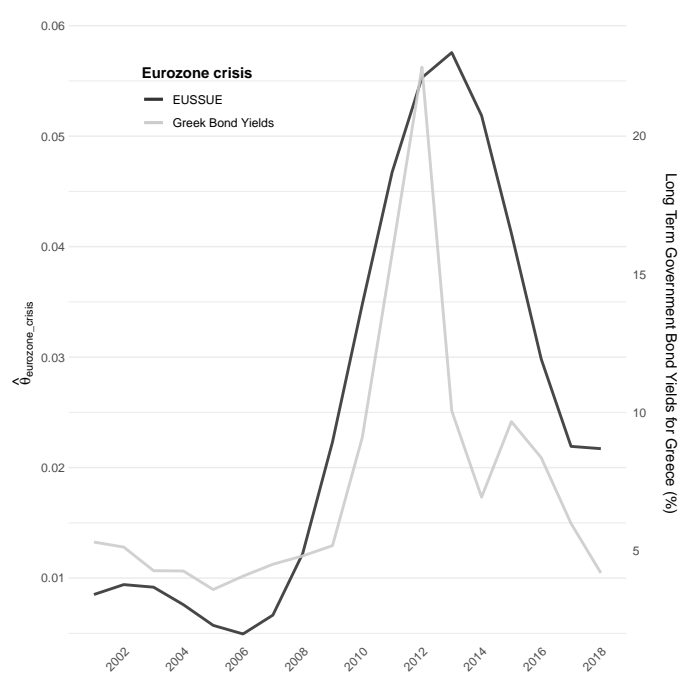

(a) Eurozone crisis

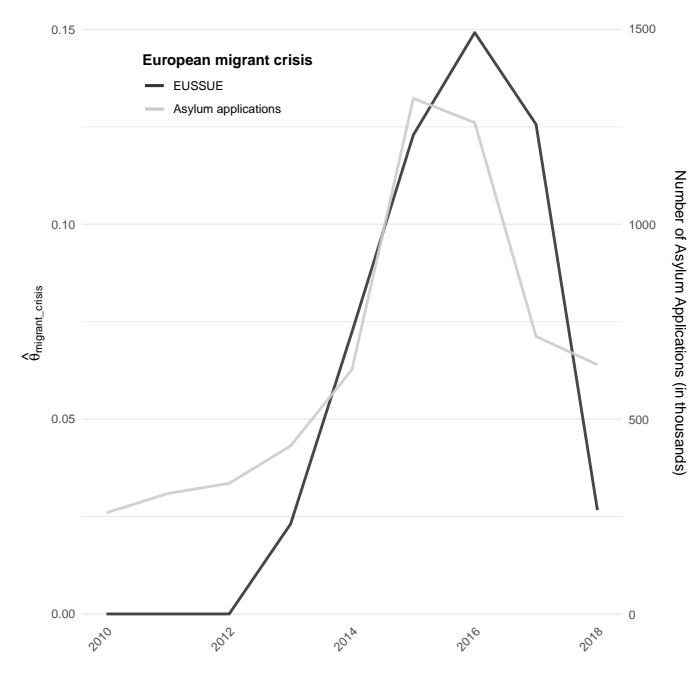

(b) Migrant crisis

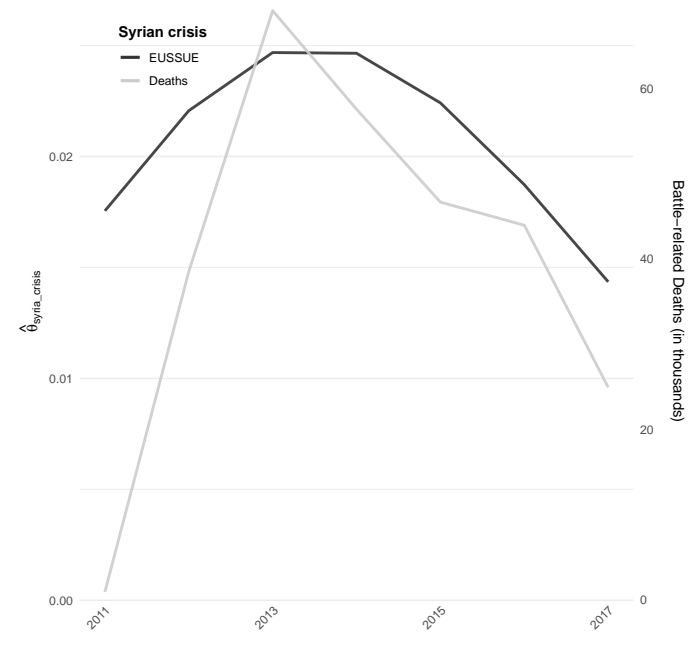

(c) Syria crisis

Figure 8: Temporal patterns of four EUSSUE topics and related external measures. Greek bond yields and the number of asylum application are sourced from Eurostat and battle-related deaths in Syria from the World Bank. On the left vertical axis is the estimated proportion of a given topic $\hat{\theta}_{s}$ where $s \in[1,75]$, while the external indicator is measured on the right vertical axis.

The temporal patterns of external measures largely overlap with EUSSUE topics. The trends support the plausible assumption that issue attention varies for the most part in step with crisis intensity. Crises tend to generate and subsequently lose EUlevel attention rapidly.

To assess the statistical strength of these relationships, Table 5 presents the results of several linear regressions, taking the EUSSUE topic proportions as the dependent variable and the external indicators as predictors. The Table reports effect sizes and 
95\% confidence intervals with bootstrap standard errors ${ }^{19}$ The estimates of the external measures are positive and significant at $\alpha=5 \%$.

Table 5: Relationship between three EUSSUE topics and thematically connected realworld quantities.

\begin{tabular}{|c|c|c|c|}
\hline & \multicolumn{3}{|c|}{ Estimated Topic Proportion $\left(\hat{\theta}_{s}\right)$} \\
\hline & eurozone crisis & migrant crisis & syria crisis \\
\hline Constant & $\begin{array}{c}0.003 \\
(-0.008,0.013)\end{array}$ & $\begin{array}{c}-0.030 \\
(-0.058,-0.001)\end{array}$ & $\begin{array}{c}0.015^{* *} \\
(0.011,0.019)\end{array}$ \\
\hline Greek Long Term Bond Yields & $\begin{array}{c}0.297^{* *} \\
(0.178,0.417)\end{array}$ & & \\
\hline Asylum Applications & & $\begin{array}{c}0.135^{* *} \\
(0.094,0.176)\end{array}$ & \\
\hline Battle-related Deaths & & & $\begin{array}{c}0.137^{*} \\
(0.042,0.232) \\
\end{array}$ \\
\hline Observations & 18 & 11 & 7 \\
\hline $\mathrm{R}^{2}$ & 0.598 & 0.821 & 0.613 \\
\hline Adjusted $\mathrm{R}^{2}$ & 0.573 & 0.801 & 0.536 \\
\hline Residual Std. Error & $0.012(\mathrm{df}=16)$ & $0.026(\mathrm{df}=9)$ & $0.003(\mathrm{df}=5)$ \\
\hline F Statistic & $23.849^{* * *}(\mathrm{df}=1 ; 16)$ & $41.201^{* * *}(\mathrm{df}=1 ; 9)$ & $7.930^{* *}(\mathrm{df}=1 ; 5)$ \\
\hline
\end{tabular}

Note. ${ }^{*} \mathrm{p}<0.05 ;{ }^{* *} \mathrm{p}<0.01$; Number of bootstrap iterations is 10.000 .

\section{Conclusion}

In this paper we presented a new measure of issue attention at the EU level, EUSSUE. Constructed from Agence Europe daily bulletins using a combination of human and computerized text-classification methods, EUSSUE provides a generic EU-level measure of issue prevalence across 75 topics organized in 19 policy themes. Our validation exercise shows that it constitutes a reliable measure of the issues discussed in the entire universe of Agence Europe bulletins published in English in the period 19792018. EUSSUE should be seen as a complement rather than a substitute to existing, actor-based indicators of agenda priority like the Agendas Project.

We believe that our measure of issue attention should be of broad interest to the EU studies research community. How the Brussels bubble reacts to world events and major crises is just one illustration. The generic nature of the EUSSUE dataset opens the possibility for researchers to deploy it - in entirety or in part - in different ways and contexts to investigate items of both low and high politics. Our indicator can be used as a dependent variable to explain variation in issue attention; as an independent variable to explain other phenomena; or as a control variable to remove the effect of

\footnotetext{
${ }^{19}$ The normality assumption in the regression analysis is likely to be violated and bootstrapping permits to relax this assumption by producing robust standard errors.
} 
varying issue saliency on a causal relationship of interest. Alternatively, researchers may also decide to use the underlying textual corpus or the pre-processed data in order to, for example, remodel the topic space in a way tailored to specific research objectives or to apply supervised classification techniques. 


\section{References}

Adam, B. P. S. and B. Eschner

2008. The contribution of the press to Europeanization of public debates. Journalism: Theory, Practice \& Criticism, 9(4):465-492.

Alexandrova, P.

2017. Institutional issue proclivity in the eu: the european council vs the commission. Journal of European Public Policy, 24:755-774.

Alexandrova, P., M. Carammia, S. Princen, and A. Timmermans

2014. Measuring the European Council agenda: Introducing a new approach and dataset. European Union Politics, 15:152-167.

Alexandrova, P., M. Carammia, and A. Timmermans

2012. Policy punctuations and issue diversity on the european council agenda. Policy Studies Journal, 40(1):69-88.

Alexandrova, P., A. Rasmussen, and D. Toshkov

2016. Agenda responsiveness in the European Council: Public priorities, policy problems and political attention. West European Politics, 39:605-627.

Arghyrou, M. and A. Kontonikas

2012. The EMU sovereign debt crisis: Fundamentals, expectations and contagion. Journal of International Financial Markets, Institutions and Money, 22:658-677.

Bastin, G.

2002. L'europe saisie par l'information (1952-2001): des professionnels du journalisme engagé aux content coordinators. Cahiers Politiques, Pp. 19-41.

Baumgartner, F., C. Green-Pedersen, and B. Jones

2006. Comparative studies of policy agendas. Journal of European Public Policy, 13:959-74.

Baumgartner, F. and B. Jones

1993. Agendas and Instability in American Politics. University of Chicago Press.

Beyers, J., A. Dür, and A. Wonka

2018. The political salience of EU policies. Journal of European Public Policy, 25:1726-1737.

Blei, D. M.

2012. Probabilistic topic models. Communications of the ACM, 55(4):77-84. 
Blei, D. M. and J. D. Lafferty

2006. Dynamic topic models. In Proceedings of the 23rd international conference on Machine learning, Pp. 113-120. ACM.

Blei, D. M., J. D. Lafferty, et al.

2007. A correlated topic model of science. The Annals of Applied Statistics, 1(1):1735 .

Blei, D. M., A. Y. Ng, and M. I. Jordan

2003. Latent dirichlet allocation. Journal of Machine Learning Research, 3(Jan):993-1022.

Boydstun, A. E.

2013. Politics, the Media, and Agenda Setting. University of Chicago Press.

Busby, A.

2013. 'bursting the brussels bubble': Using ethnography to explore the european parliament as a transnational political field. Perspectives on European Politics and Society, 14(2):203-222.

Bäckstrand, K. and O. Elgström

2013. The EU's role in climate change negotiations: From leader to 'leadiator'. Journal of European Public Policy, 20:1369-1386.

Carammia, M., S. Princen, and A. Timmermans

2016. From summitry to EU government: An agenda formation perspective on the European Council. Journal of Common Market Studies, 54:809-825.

Carmines, E. G. and J. A. Stimson

1989. Issue Evolution: Race and the Transformation of American Politics. Princeton University Press.

Catalinac, A.

2016. From pork to policy: The rise of programmatic campaigning in japanese elections. Journal of Politics, 78:1-18.

Chang, J., S. Gerrish, C. Wang, J. L. Boyd-Graber, and D. M. Blei

2009. Reading tea leaves: How humans interpret topic models. In Advances in neural information processing systems, Pp. 288-296.

De Bruycker, I. and J. Beyers

2015. Balanced or biased? interest groups and legislative lobbying in the European news media. Political Communication, 32:453-474. 
Denny, M. J. and A. Spirling

2018. Text preprocessing for unsupervised learning: Why it matters, when it misleads, and what to do about it. Political Analysis, 26(2):168-189.

Diez-Medrano, J.

2004. Framing Europe. Attitudes to European Integration in Germany, Spain, and the United Kingdom. Princeton University Press.

Dimitrov, R. S.

2010. Inside copenhagen: The state of climate governance. Global Environmental Politics, 10:18-24.

Dybowski, T. P. and P. Adämmer

2018. The economic effects of u.s. presidential tax communication: Evidence from a correlated topic model. European Journal of Political Economy, 55:511-525.

Dür, A. and G. Mateo

2014. Public opinion and interest group influence: how citizen groups derailed the anti-counterfeiting trade agreement. Journal of European Public Policy, 21:11991217.

Fougier, E.

2010. Le journalisme européen, un bien nécessaire. L'Europe en Formation, (3):149173.

Greene, D. and J. P. Cross

2017. Exploring the political agenda of the european parliament using a dynamic topic modelling approach. Political Analysis, 25:77-94.

Grimmer, J.

2010. A bayesian hierarchical topic model for political texts: Measuring expressed agendas in senate press releases. Political Analysis, 18:1-35.

Grimmer, J. and B. M. Stewart

2013. Text as data: The promise and pitfalls of automatic content analysis methods for political texts. Political Analysis, 21(03):267-297.

Groen, L. and A. Niemann

2013. The European Union at the Copenhagen climate negotiations: A case of contested EU actorness and effectiveness. International Relations, 27:308-324. 
Häge, F. M.

2016. Political attention in the council of the european union: A new dataset of working party meetings, 1995-2014. European Union Politics, 17(4):683-703.

Haug, C. and F. Berkhout

2010. Learning the hard way? European climate policy after Copenhagen. Environment: Science and Policy for Sustainable Development, 52:20-27.

Hruschka, D. J., D. Schwartz, D. C. St. John, E. Picone-Decaro, R. A. Jenkins, and J. W. Carey

2004. Reliability in coding open-ended data: Lessons learned from HIV behavioral research. Field methods, 16(3):307-331.

Kim, S. E.

2018. Media bias against foreign firms as a veiled trade barrier: Evidence from chinese newspapers. American Political Science Review, 112:954-970.

Klüver, H.

2011. The contextual nature of lobbying: explaining lobbying success in the european union. European Union Politics, 12:483-506.

Koopmans, R.

2007. Who inhabits the european public sphere? winners and losers, supporters and opponents in europeanised political debates. European Journal of Political Research, 46:183-210.

Koopmans, R. and B. Pfetsch

2006. Obstacles or motors of europeanization? german media andthe transnationalization of public debate. Communications, 31:115-138.

Lucas, C., R. A. Nielsen, M. E. Roberts, B. M. Stewart, A. Storer, and D. Tingley 2015. Computer-assisted text analysis for comparative politics. Political Analysis, $23(2): 254-277$.

Manganelli, S. and G. Wolswijk

2009. What drives spreads in the Euro area government bond market? Economic Policy, 24:191-240.

Marthoz, J.-P.

2008. Journalisme international. De Boeck Supérieur. 
Mimno, D., H. M. Wallach, E. Talley, M. Leenders, and A. McCallum

2011. Optimizing semantic coherence in topic models. In Proceedings of the conference on empirical methods in natural language processing, Pp. 262-272. Association for Computational Linguistics.

Netjes, C. E. and H. A. Binnema

2007. The salience of the european integration issue: Three data sources compared. Electoral Studies, 26(1):39-49.

Oberthür, S.

2011. The European Union's performance in the international climate change regime. Journal of European Integration, 33:667-682.

Ooms, J.

2017. Hunspell: High-performance stemmer, tokenizer, and spell checker for $\mathrm{r}$. r package version 2.3. available at: https://CRAN. R-project.org/package= hunspell.

Osnabrügge, M.

2015. The european commission and the implementation of its legislative programme. European Union Politics, 16(2):241-261.

Peter, J. and C. De Vreese

2004. In search of Europe. A cross-national comparative study of the European Union in national television news. The International Journal of Press / Politics, 9:3-24.

Peters, G.

1994. Agenda-setting in the european community. Journal of European Public Policy, 1:9-26.

Princen, S.

2007. Agenda-setting in the european union: a theoretical exploration and agenda for research. Journal of European Public Policy, 14:21-38.

Princen, S.

2011. Agenda-setting strategies in eu policy processes. Journal of European Public Policy, 18:927-943.

Princen, S. and M. Rhinard

2006. Crashing and creeping: agenda-setting dynamics in the european union. Journal of European Public Policy, 13:1119-1132. 
Quinn, K. M., B. L. Monroe, M. Colaresi, M. H. Crespin, and D. R. Radev 2010. How to analyze political attention with minimal assumptions and costs. American Journal of Political Science, 54:209-228.

Rauh, C.

2014. Communicating supranational governance? the salience of EU affairs in the german bundestag, 1991-2013. European Union Politics, 16(1):116-138.

Risse, T.

2010. A Community of Europeans? Transnational Identities and Public Spheres. Cornell University Press.

Roberts, M. E., B. M. Stewart, and D. Tingley

2019. stm: R package for structural topic models. Journal of Statistical Software.

Roberts, M. E., B. M. Stewart, D. Tingley, C. Lucas, J. Leder-Luis, S. K. Gadarian, B. Albertson, and D. G. Rand

2014. Structural topic models for open-ended survey responses. American Journal of Political Science, 58:1064-1082.

Rosen-Zvi, M., T. Griffiths, M. Steyvers, and P. Smyth

2004. The author-topic model for authors and documents. In Proceedings of the 20th conference on Uncertainty in artificial intelligence, Pp. 487-494. AUAI Press.

Rothschild, J. E., A. J. Howat, R. M. Shafranek, and E. C. Busby 2019. Pigeonholing partisans: Stereotypes of party supporters and partisan polarization. Political Behaviour.

Smith, R.

2007. An overview of the tesseract ocr engine. In Ninth International Conference on Document Analysis and Recognition (ICDAR 2007), volume 2, Pp. 629-633. IEEE.

Sorace, M.

2018. The european union democratic deficit: Substantive representation in the european parliament at the input stage. European Union Politics, 19:3-24.

Veen, T.

2011. Positions and salience in European Union politics: Estimation and validation of a new dataset. European Union Politics, 12(2):267-288.

Wallach, H. M., I. Murray, R. Salakhutdinov, and D. Mimno 2009. Evaluation methods for topic models. In Proceedings of the 26th annual international conference on machine learning, Pp. 1105-1112. ACM. 
Warntjen, A.

2012. Measuring salience in eu legislative politics. European Union Politics, 13:168182.

Wlezien, C.

2005. On the salience of political issues: The problemwith 'most important problem'. Electoral Studies, 24:555-579.

Wonka, A.

2016. The party politics of the euro crisis in the german bundestag: frames, positions and salience. West European Politics, 39:125-144.

Årup Nielsen, F.

2011. A new ANEW: Evaluation of a word list for sentiment analysis in microblogs. CEUR Workshop Proceedings, 718:93-98. 


\section{Appendix}

\section{Number of words per document}

The news cycle is not uniform during the course of a year. As visible in Figure 9, the summer months (in particular August) see reduced activity reflected also in shorter AEB issues.

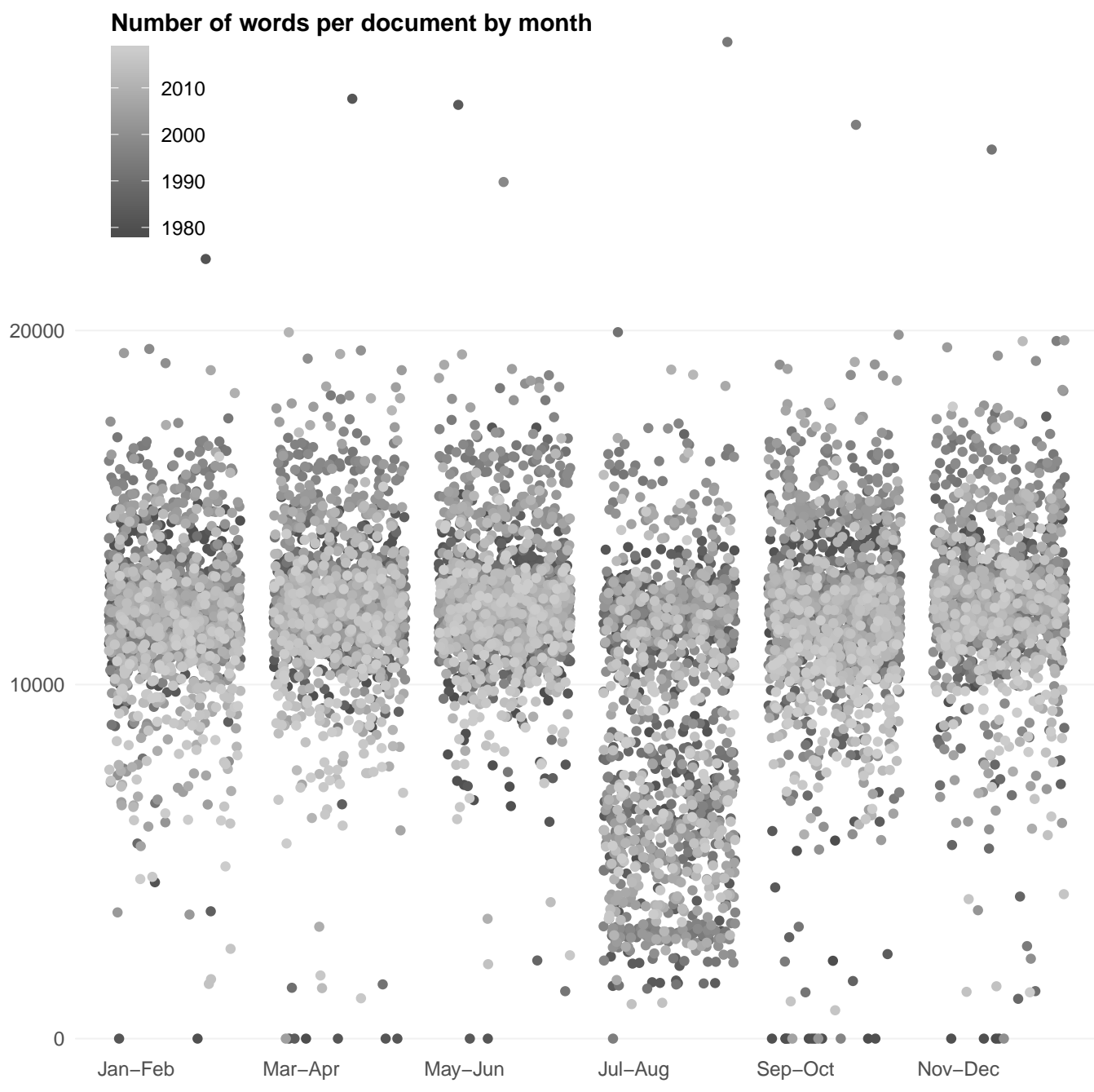

Figure 9: AEB issues are systematically shorter during the summer.

\section{List of custom words removed}

In the pre-processing stage we created a list of words which were deemed unhelpful for the interpretation of the STM results. The list contains words peculiar to the data source, prepositions, conjunctions verbs and others. These words were removed at the first stage of the data reduction process (see Figure 2). 
Table 6: Custom words removed from the textual corpus.

\begin{tabular}{ll}
\hline \hline Type & Words \\
\hline \multirow{2}{*}{ Short } & des sur der die das les see will eur ecu une von van aus eec frg mrs rue con fax one two tel six par pas ces cee \\
& son ses und s.a nnn den com sir non dont est bei new end year can put e.p eec's e.e.c eu's eee top l.c o.l b.c a.b \\
& h.b e.h n.s n.s. due mon tues isbn ten act http www iil etc ing ion tion hue dent \\
Bulletin & bulletin agence series serie transl.fl transl.jl transl.rt transl.rh gazzo riccardi ferdinando page pages telex book \\
& event library transl publish published publishing publishes editor editorial editing edited edit editor's editorials \\
& editors mathieu lionel letter e-mail email website volume events pascal korbys bion changeur aminata niang \\
& solenn paulec hansens gesant petitjean sophie ferdina ferdinan ferdinand ricc ricca riccar riccard ric hagry em- \\
& manuel original version versions french translate translated news new originally subscription subscrip subscribe \\
& press release university author authors author's universities university's professor professor's professors language \\
& study studies study's info bookshop subscriber subscribers subscribed distribute distributed office distributes \\
& internet idea publication publication's publications report
\end{tabular}

European europe european europa europe's union union's community community's eu eu's furopean furope session ecus mecus fifteen twelve nine strasbourg brussels meeting luxembourg commission commissioner mep meps spokesperson

French pour européenne européen européennes européens politique l'europe président société bruxelles banque principe principement communautaire communautaires comme faire mondial mondiale d'information petit petits petite petites uniquement telles telle orienter probablement optionelle internationale pays belgique sans rédacteur quotidien bruxellois que dans nouvel nouvelle nouvelles nouvels abonnement abonnements thé paris allemand allemande bonito saint

Leaders romano prodi catherine juncker jean-claude jean barroso miguel thorn delors jacques santer leon brittan javier federica giscard d'estaing verhaegen tindeman julian king herman rompuy decors saner donald tusk

Month january february march april june july august september october may november december jan feb mar apr jun jul aug sep oct nov dec janvier février mars avril mai juin julliet août aout septembre octobre novembre décembre februari januari maart mei juni juli augustus oktober month year

Days monday tuesday wednesday thursday friday saturday sunday mon tue wed thu fri sat sun yesterday day today tomorrow week

Other mainly primarily notably presumably preferably particularly behalf concem other behind upon first last also according part level certain possible well already three now next view within without still number place way necessary role including favour current main period different total towards long issue issues problem problems area areas able point results like months weeks years major among specific far better less more many allow just four former present particular position million billion sector situation time general affairs fact subject opinion conditions plan interest term talks activities text visit programme programmes example importance possibility terms hand currently whole addition moreover form matter another request especially efforts initiative several important announced future report mitre neuron after although as if though because before even lest once unless until since whenever wherever while whatever where both either neither whether however nevertheless nonetheless given therefore thus whereas wherea aspect approach field eureka silly cleric pianism outgoing back forward focus practice subsequent previous tonnes tonne ton

Verbs shall following called calls recall recalls recalled calling discuss discussed declared declare declares regarding concernement concern concerning concerns concerned reflects reflected look looks looking conceming concemed concems said say says must made take make use held holds hold decided expected added ensure continue based give used taking taken provide come means stressed stresses help making asked expressed want wants wanted intended intends proposed proposes increase set need support adopted account respect change approve approved approves points pointed launch welcome welcomes welcomed explain explained explains informed informs regards regarded analyse analysed analyses examined examines examine participate participated stated call present presented presents noted compared compare agreed agree agrees regard meet describe announce announced announces announcing allow allows allowed provided reached considered confirmed met granted signed aimed applied received receive prepared established brought takes include including promoted launched sent continued contribute trengthen establish encourage achieve organise organised felt seems requested obtain hopes maintain related affected facilitate ensuring promoting opening feels seeking completed reiterated reaffirmed dealing constitutes constituted constituting repeating identify repeated concluded recording excluding assessing assessed assess analysing changing changed recommend recommended recommending introduced introduces introducing introduce offer involve involved involves involving become becomes becoming became indicate believe believed indicated indicating tackle tackled tackling tackles focusing focused focuses drawing needing needs needed note noting notes 


\section{Examples of STM output}

The $\beta$ and $\theta$ values output by the STM are the most valuable information about the model topics. We provide several visualizations here with the rest available online ${ }^{20}$

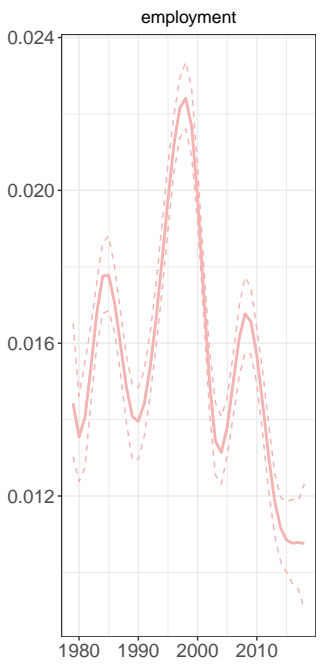

(a) Employment
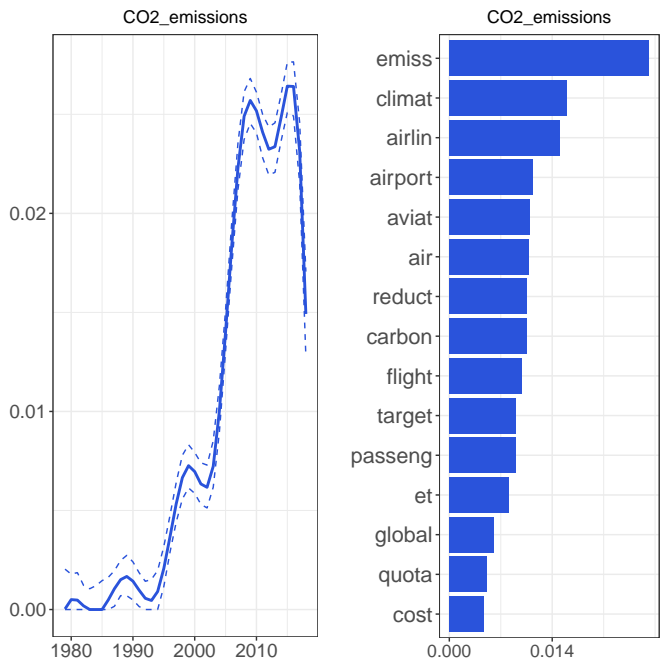

(c) $\mathrm{CO} 2$ emissions
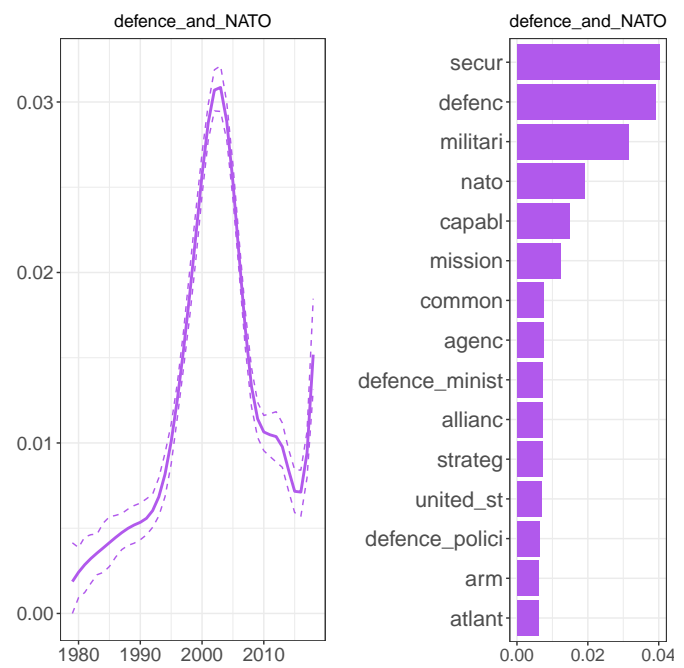

(b) Defence and NATO
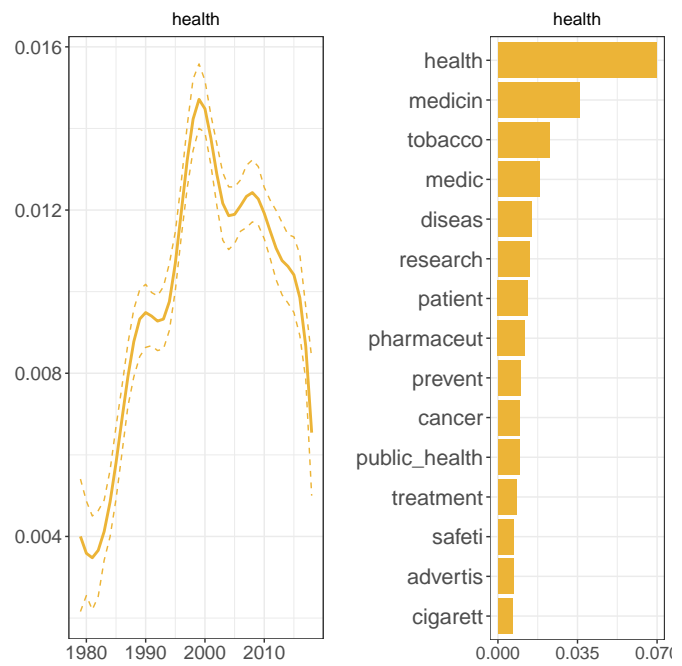

(d) Health

Figure 10: Estimated topic proportion over time $\hat{\theta}$ and top 15 words by $\hat{\beta}$ associated with topic.

In addition to these plots, we also used the document with the highest topical proportion to guide our choice of topic labels. The following is an excerpt from a document with the highest $\theta$ value for topic "CO2_emissions":

Mission accomplished for the German presidency of the European Council and the G8, after it made an integrated energy and climate strategy an

\footnotetext{
${ }^{20}$ https://eussue.shinyapps.io/eussue_shiny/
} 
absolute priority in the fight against climate change - a global phenomenon which requires an urgent and determined response if we wish to avoid catastrophic consequences. In Brussels on 9 March, the heads of state and government of the 27 EU member states backed a policy, unanimously described as ambitious, to combat climate change post 2012. There was no difficulty in their subscribing to a target of a 30\% reduction (compared with 1990 levels) in greenhouse gases for all industrialized countries by 2020 (and $60-80 \%$ reductions by 2050), and to agree to a unilateral $20 \%$ reduction in EU emissions if the other countries refused to come on board in international negotiations. This undertaking is binding, as the European Commission, with the agreement of the Environment and Energy Council, proposed in its energy and climate package of 10 January.

For the AEB corpus the top documents provide usually only limited guidance, as each AEB issue contains a variety of news items on different topics. The top $\theta$ document might be more useful in the interpretation of topic models of other textual corpora.

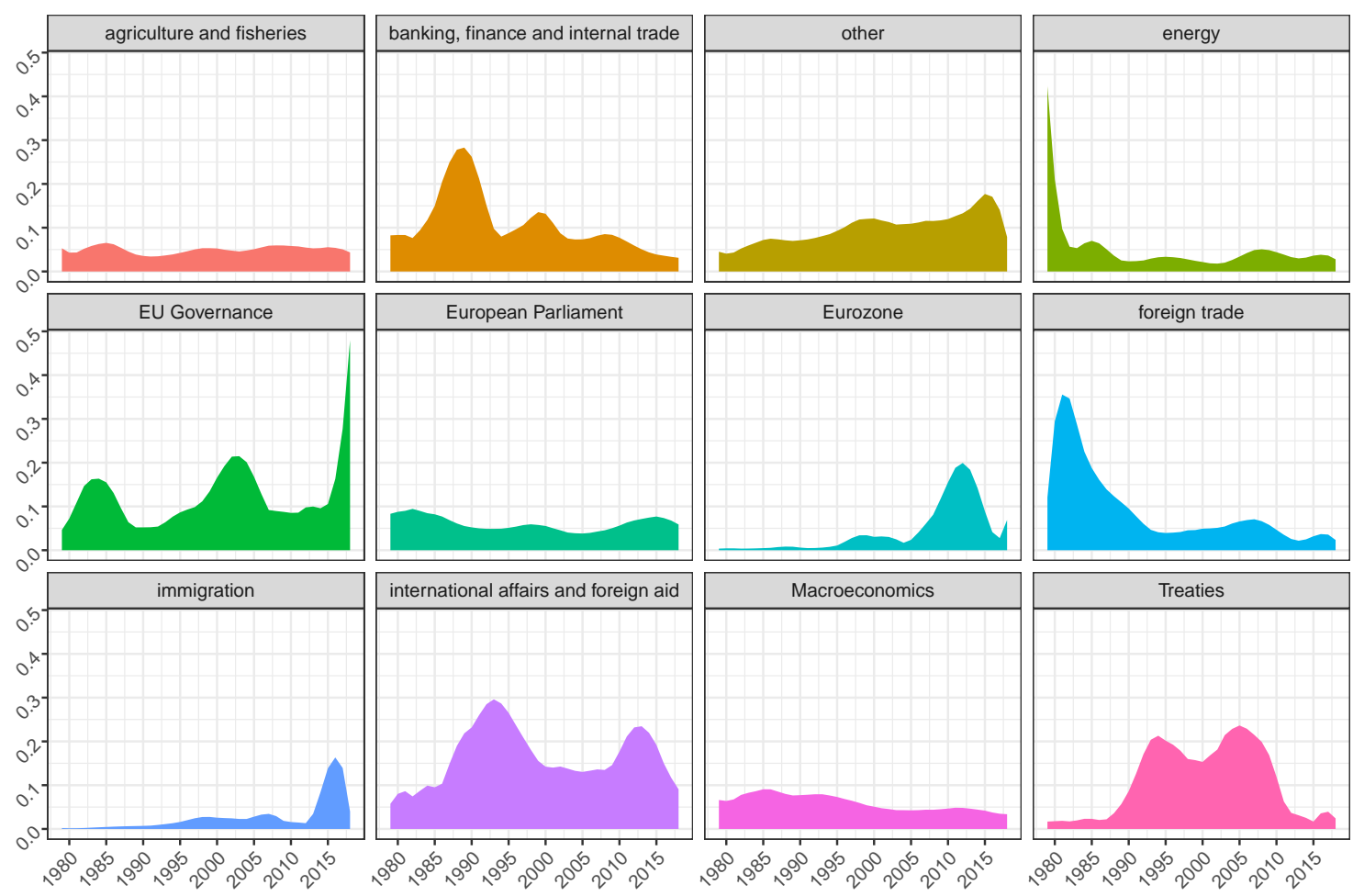

Figure 11: EUSSUE theme proportion over time 


\section{Metric-based topic clustering}

Model topics can also be clustered using distance and similarity measures, and visualized as, for example (Quinn et al., 2010), a dendogram. Clustering still requires that the user chooses the number of clusters, although as in the case of the number of topics, heuristic methods to determine the optimal number of clusters exist. In Figure 12 we show a 9-cluster dendogram for the 75 topic EUSSUE measure.

Cluster Dendogram (9 Clusters, 75 Topics)

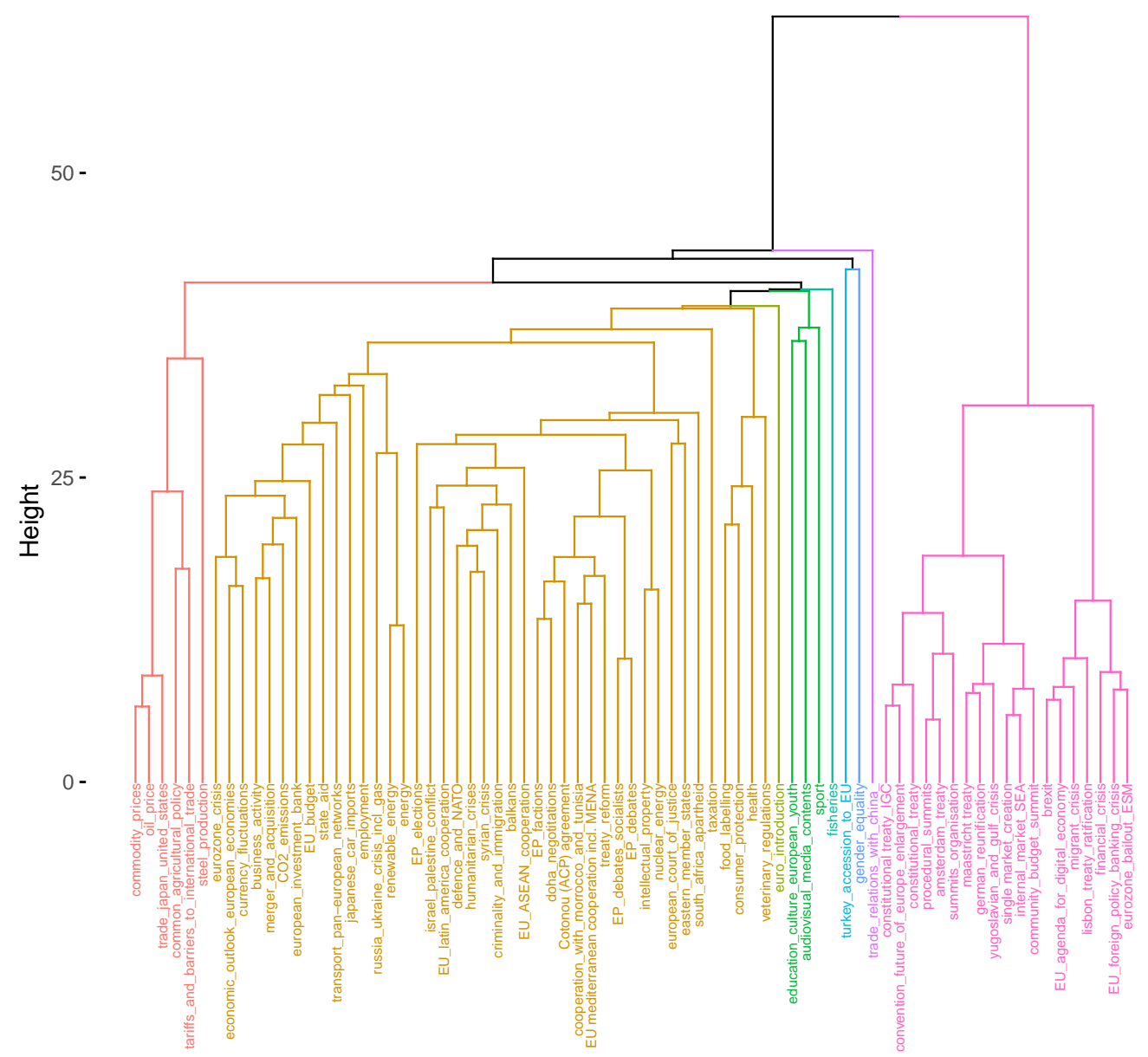

Figure 12: 9-cluster dendogram of 75 EUSSUE topics.

While the proximity of some topics makes intuitive sense (for example consumer protection and food labelling), other associations are more difficult to interpret. In fact we can see the clustering algorithm to pick up on similarities between topics which are salient at roughly the same moment in time (for example Brexit and EU digital agenda). These temporal relationships are not particularly useful from the perspective of our objective to construct a dynamic measure of issue attention. 


\section{Inter-coder reliability}

In the validation exercise we employed human coders to manually classify randomly sampled documents on the basis of our machine-generated classification. We had three documents coded by five persons in order to get a more robust sense of intercoder reliability. Figure 13 shows the correlation among five coders' determination of presence of topics in the sample documents. The average level of agreement among these five coders was similar to the values obtained for the rest of the documents, which were coded by two persons.

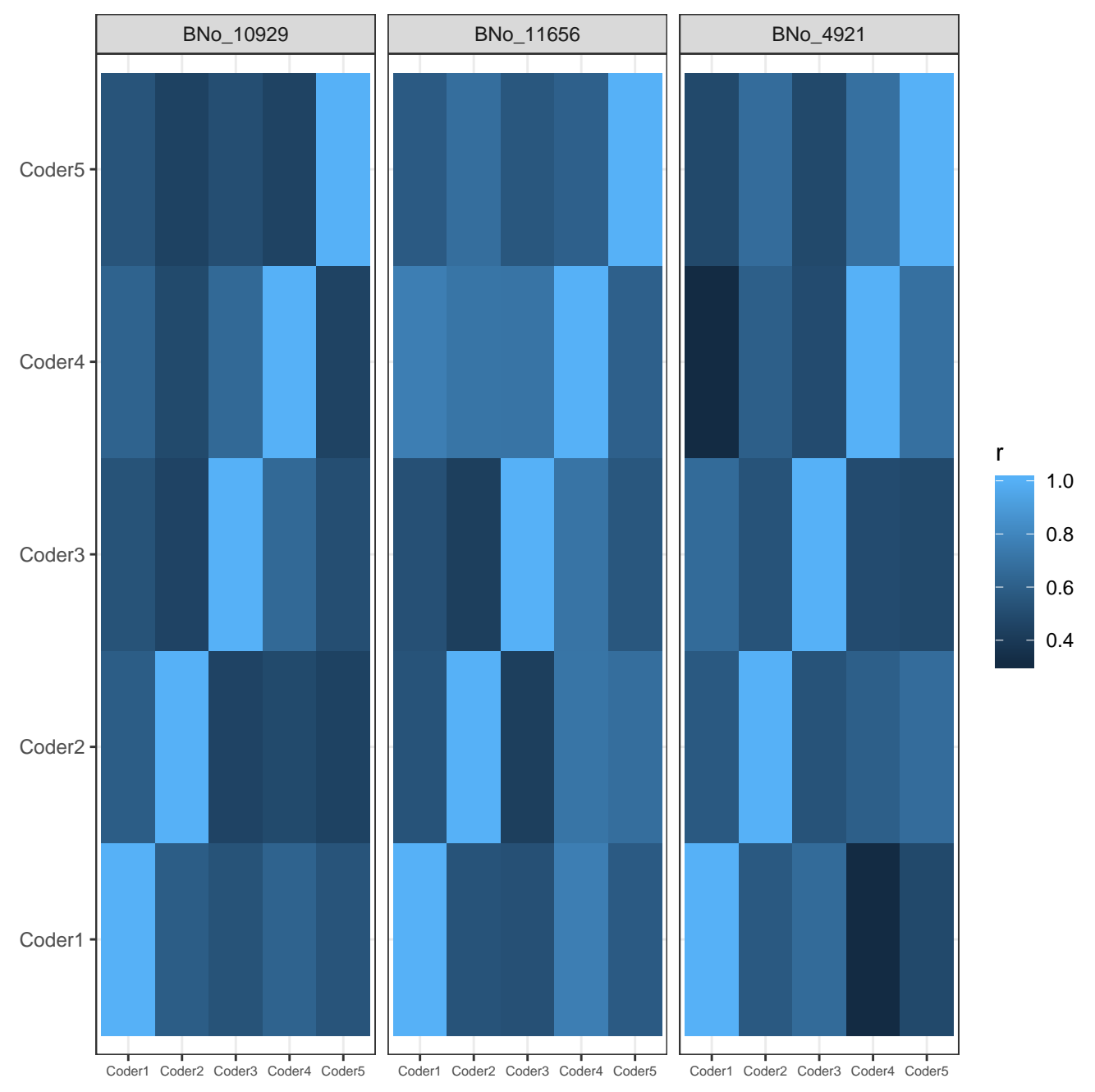

Figure 13: Correlation matrix showing inter-coder reliability for three randomly sampled AEB documents. 
Table 7: Correlation between EUSSUE theme proportions and human coding at theme level for a random sample of Agence Europe bulletins.

\begin{tabular}{|c|c|c|}
\hline & Pearson & Spearman \\
\hline macroeconomics & $\begin{array}{c}0.965^{* * *} \\
(0.965 ; 0.965)\end{array}$ & $\begin{array}{c}0.74^{* * *} \\
(0.185 ; 1.295)\end{array}$ \\
\hline civil rights, minority issues and civil liberties & $\begin{array}{c}0.968^{* * *} \\
(0.968 ; 0.968)\end{array}$ & $\begin{array}{c}0.667^{* *} \\
(0.083 ; 1.251)\end{array}$ \\
\hline health & $\begin{array}{c}0.778^{* * *} \\
(0.235 ; 1.321)\end{array}$ & $\begin{array}{c}0.357 \\
(-0.287 ; 1.001)\end{array}$ \\
\hline agriculture and fisheries & $\begin{array}{c}0.956^{* * *} \\
(0.956 ; 0.956)\end{array}$ & $\begin{array}{c}0.641^{* *} \\
(0.047 ; 1.235)\end{array}$ \\
\hline labour and employment & $\begin{array}{c}0.955^{* * *} \\
(0.955 ; 0.955)\end{array}$ & $\begin{array}{c}0.565^{*} \\
(-0.047 ; 1.177)\end{array}$ \\
\hline education & $\begin{array}{c}0.700^{* *} \\
(0.13 ; 1.27)\end{array}$ & $\begin{array}{c}0.327 \\
(-0.319 ; 0.973)\end{array}$ \\
\hline environment & $\begin{array}{c}0.748^{* * *} \\
(0.195 ; 1.301)\end{array}$ & $\begin{array}{c}0.381 \\
(-0.261 ; 1.023)\end{array}$ \\
\hline energy & $\begin{array}{c}0.891^{* * *} \\
(0.891 ; 0.891)\end{array}$ & $\begin{array}{c}0.355 \\
(-0.29 ; 1)\end{array}$ \\
\hline immigration & $\begin{array}{c}0.742^{* * *} \\
(0.185 ; 1.299)\end{array}$ & $\begin{array}{c}0.744^{* * *} \\
(0.186 ; 1.302)\end{array}$ \\
\hline banking, finance and internal trade & $\begin{array}{c}0.979^{* * *} \\
(0.979 ; 0.979)\end{array}$ & $\begin{array}{c}0.668^{* *} \\
(0.083 ; 1.253)\end{array}$ \\
\hline space, science, technology and communication & $\begin{array}{c}0.943^{* * *} \\
(0.943 ; 0.943)\end{array}$ & $\begin{array}{c}0.576^{*} \\
(-0.034 ; 1.186)\end{array}$ \\
\hline international affairs and foreign aid & $\begin{array}{c}0.970^{* * *} \\
(0.97 ; 0.97)\end{array}$ & $\begin{array}{c}0.772^{* * *} \\
(0.233 ; 1.311)\end{array}$ \\
\hline defence & $\begin{array}{c}0.856^{* * *} \\
(0.348 ; 1.364)\end{array}$ & $\begin{array}{c}0.465 \\
(-0.167 ; 1.097)\end{array}$ \\
\hline transportation & $\begin{array}{c}0.846^{* * *} \\
(0.344 ; 1.348)\end{array}$ & $\begin{array}{c}0.201 \\
(-0.445 ; 0.847)\end{array}$ \\
\hline foreign trade & $\begin{array}{c}0.956^{* * *} \\
(0.956 ; 0.956)\end{array}$ & $\begin{array}{c}0.397 \\
(-0.243 ; 1.037)\end{array}$ \\
\hline EU governance & $\begin{array}{c}0.968^{* * *} \\
(0.968 ; 0.968)\end{array}$ & $\begin{array}{c}0.809^{* * *} \\
(0.276 ; 1.342)\end{array}$ \\
\hline
\end{tabular}

Note. ${ }^{* * *} \mathrm{p}<0.01 ;{ }^{* *} \mathrm{p}<0.05 ;^{*} \mathrm{p}<0.1 ; 95 \%$

$95 \%$ confidence intervals are given in parentheses.

\section{Pre-processing robustness}

Although we have striven for maximum transparency in this domain, there are always several ways in which the text corpus can be pre-processed (Denny and Spirling, 2018). 
Here we show an alternative pre-processing specification requested by one of the reviewers. This specification differs from the one used in the paper in two respects: we remove the upper character limit (15) on tokens and the minimum document frequency (5\%) when constructing the document-term matrix. In order to avoid repeating the entire labelling and clustering exercise, we compare the results from the two specifications using, first, the heuristic approach devised by Denny and Spirling (2018) and, second, the $\theta$ distributions from the STM model.

Following Denny and Spirling (2018), we compare the two specifications according to how much they affect pairwise document similarity calculated from an "un-preprocessed" document-term matrix of the corpus. Denote $M_{1}$ a matrix of pairwise document similarity values calculated from the pre-processed document-term matrix used in the paper, $M_{2}$ the same but on the basis of a document-term matrix pre-processed according to the alternative criteria suggested by a reviewer and $M_{0}$ a baseline similarity matrix computed from a document-term matrix in which no data reduction has been carried out (see Figure 2). We find that both the absolute and rank differences between $M_{1}$ and $M_{2}$ are small, indicating that the two pre-processing specifications yield similar document-term matrices. The absolute mean difference $\frac{1}{I \times J} \sum\left|M_{1}-M_{2}\right|=0.024$ shows by how much pairwise similarity scores (a value between 0 and 1 ) differ on average if we apply the two pre-processing specifications. The rank difference between the two matrices is similarly low: after differentiating against the baseline $\left|M_{i}-M_{0}\right|$ and taking the top 10, 50 and 100 pairs (as recommended by Denny and Spirling (2018)) affected by pre-processing, we find that the mean rank difference between $M_{1}$ and $M_{2}$ is, respectively, 2.2, 9.1 and 14.8. These values are low given that there are more than 45 million degrees of freedom. The implication is that the alternative pre-processing method suggested by a reviewer results in an analysis-ready corpus that is very similar to the one we use in the paper.

We take this robustness check a step further by running the STM model used in the paper on both pre-processing specifications and comparing the theta distributions. Figure 14 shows the empirical cumulative distribution function of the theta values for the two specifications. We can see that the two distributions are very close to each other. This suggests that the theta distribution is not strongly affected by the suggested changes to pre-processing. ${ }^{21}$

\footnotetext{
${ }^{21} \mathrm{~A}$ t-test confirms that there is no significant difference between the means of the two distributions.
} 


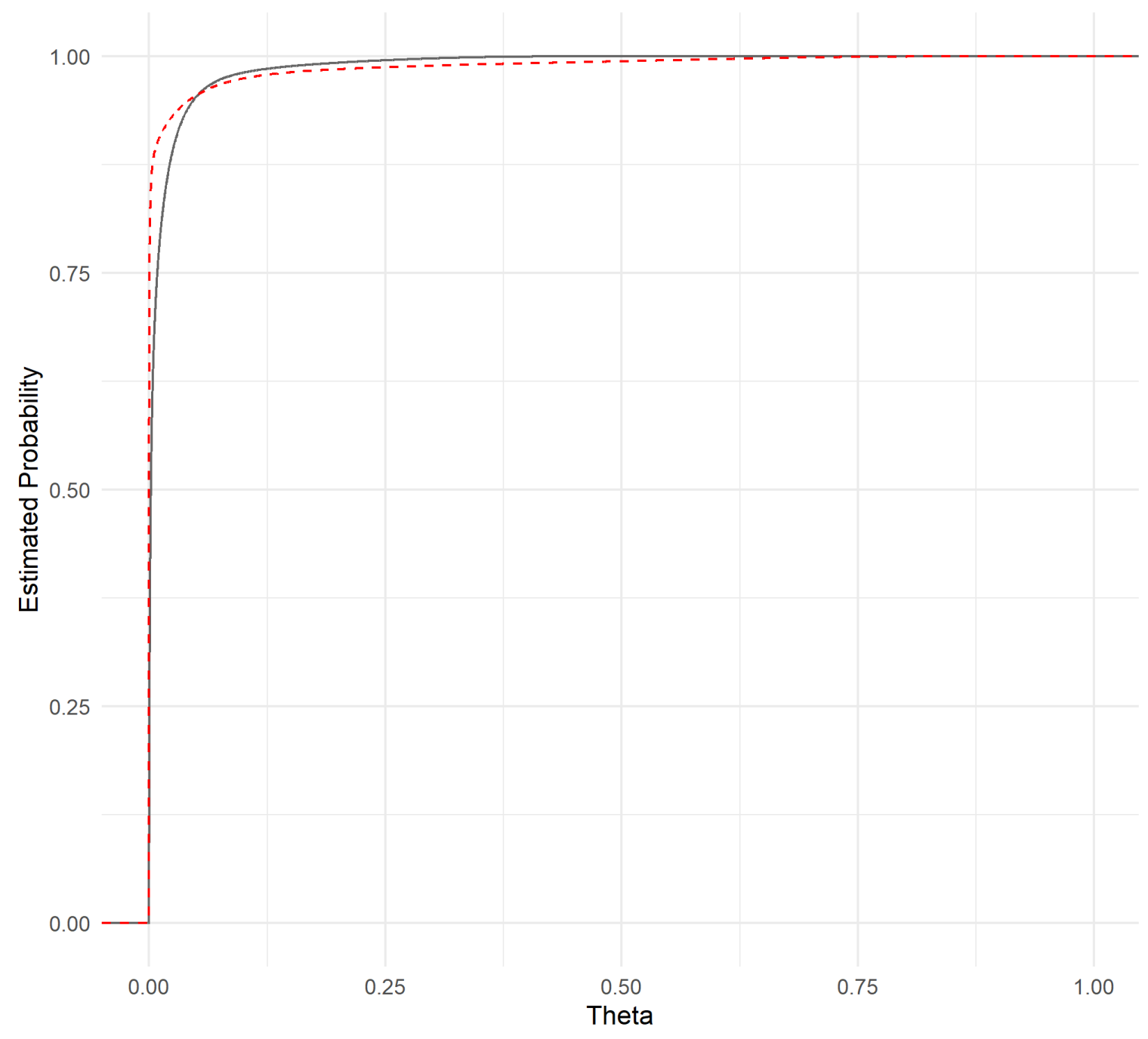

Figure 14: Empirical cumulative distribution function of theta values for two different pre-processing specifications.

Note. The dotted red line shows the results from the reviewer-suggested specification; the solid line is the distribution based on the pre-processing parameters followed in the paper.

\section{Optimal number of topics}

To evaluate the model performance at varying number of topics with

$k \in\{28,48,68,88,108,128,148\}$, we compare model selection statistics. Depicted in Figure 15 is the trade-off between semantic coherence and exclusivity for $k .22$ Ideally, we want to have topics that are both cohesive and exclusive. It can be seen that exclusivity rises and semantic coherence shrinks with a higher number of topics. 68 and 88 topics seem to strike the balance between this trade-off. Moving from $\mathrm{k}=88$ to $\mathrm{k}=108$ results in a greater loss of semantic coherence with small improvements in

\footnotetext{
${ }^{22}$ Topics are coherence in the sense that high probability words tend to appear within documents and are exclusive when top words for a topic is unlikely to appear in other topics.
} 
exclusivity levels than shifting from $\mathrm{k}=68$ to $\mathrm{k}=88$. This also indicates that the optimal $\mathrm{k}$ lies around 68 and 88 .

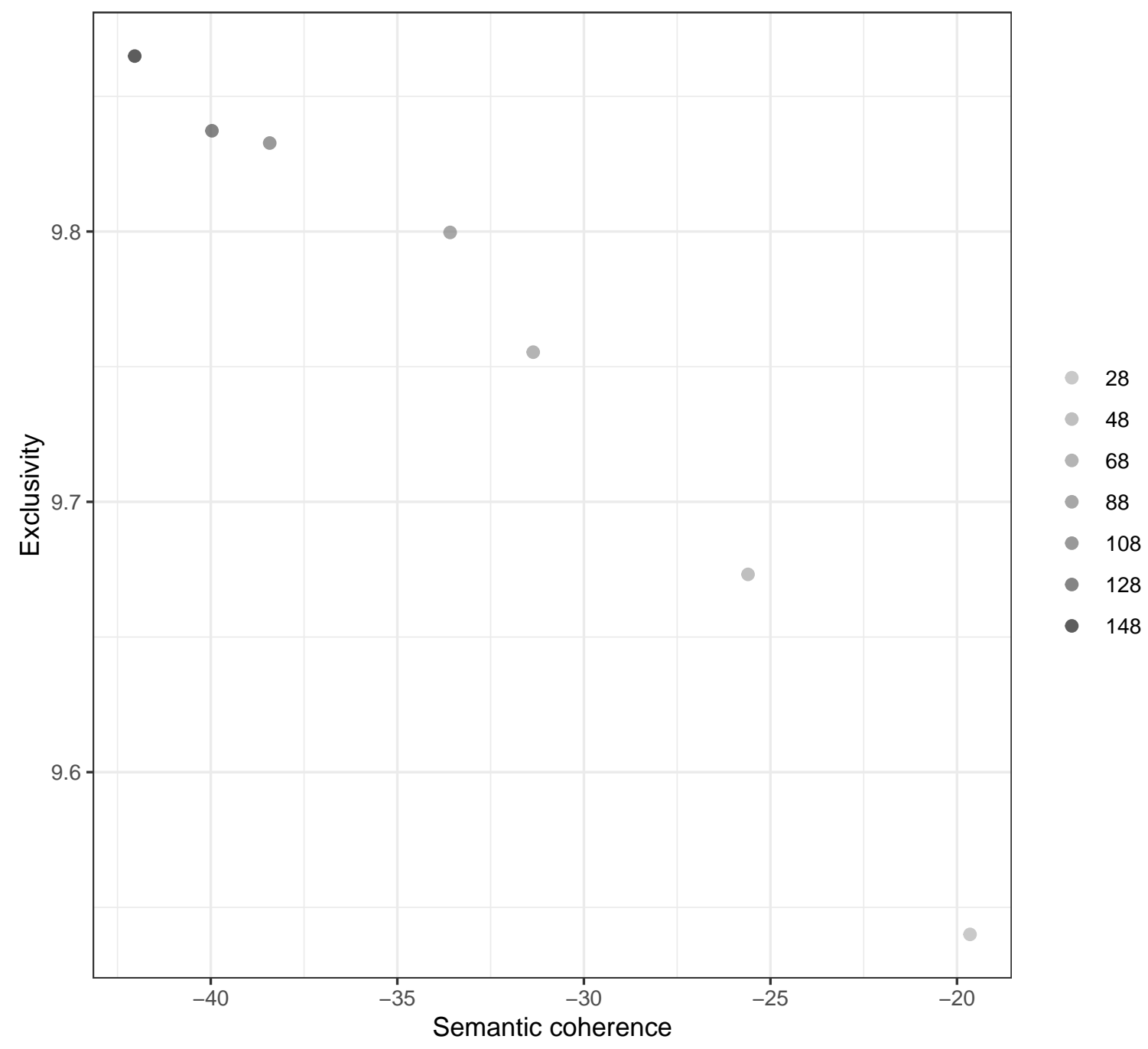

Figure 15: Optimal number of topics: Semantic Coherence versus Exclusivity

\section{Sentiment analysis}

As a measure of the neutral tone of the news reports, Figure 16 shows document-level sentiment using the AFINN lexicon (Ârup Nielsen, 2011). Mean valence per (raw) document is computed simply as the sum of valence scores of those words appearing in a document which are found in the AFINN lexicon with a non-zero value weighted by the number of token words (with a non-zero value) in the document. Average valence, though positive on average, is not far from zero - news are not overly loaded with sentiment. Nor does the average sentiment value show much temporal variation. To the extent that individual documents deviate from the general pattern, we are agnostic about the potential causes, which may be both exogenous (higher incidence of crises 
or negative news) and endogenous (changes in editorial policy).

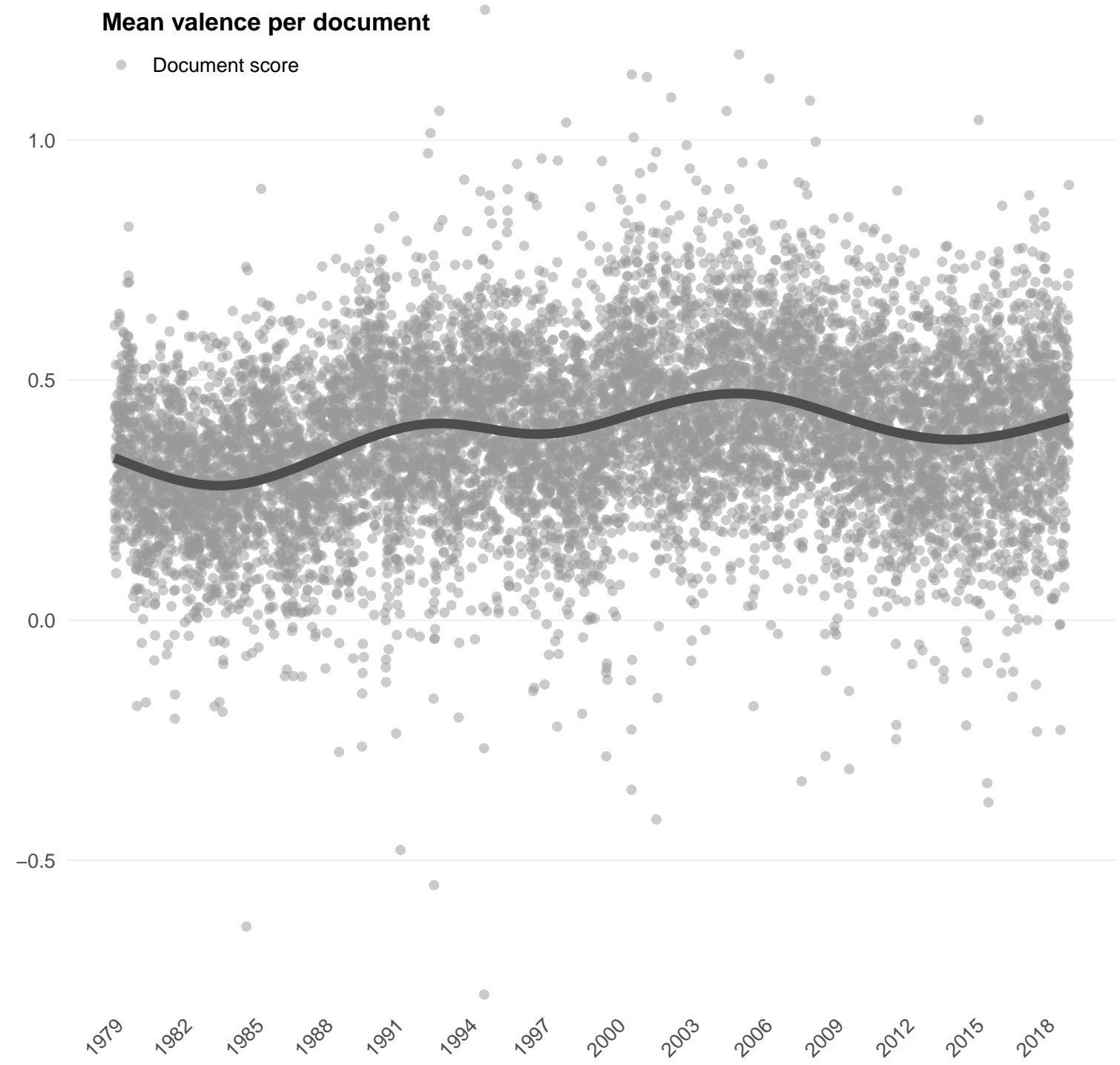

Figure 16: Sentiment analysis of documents in the raw corpus.

Our primary interested in carrying out sentiment analysis using the popular Årup Nielsen (2011) dictionary is to show over time variation in valence. Significant temporal fluctuation could indicate the presence of a previously unknown biasing factor. Although we do not observe any such critical breaks in the time-series, we believe this kind of exploratory data analysis to be good practice in preventing unpleasant surprises down the line.

For the sake of completeness, we provide here further information about the valence scores. The overall mean valence is 0.387 which means that the tone of the news is slightly positive, at least according to the Ârup Nielsen (2011) dictionary. The most common scored words are, unsurprisingly, "no" $(\mathrm{n}=409525)$ which is coded in the 
dictionary as having valence of -1 and "agreement" $(\mathrm{n}=3324389$, valence +1$)$. The third most common word is "united" $(\mathrm{n}=1777653,+1)$ which in the context of our corpus usually refers to "United States" or "United Kingdom". The most positively scored document $(\overline{\text { valence }}=1.27)$ relates to business and investment news but also commemorates the passing of the Agence Europe's longtime editor, Emanuele Gazzo. Dated 1 September 1994, the following are representative excerpts:

Electromechanics: The Franco-British group-GEC-ALSTOM is to renovate two units of a hydroelectric power station in Bula (India) in order to bring their power up to $50 \mathrm{MW}$. This contract of 129 million FF will be financed with a loan from the British Government and will comprise considerable local participation.

Building site equipment: The Japanese group KOMATSU LTD will acquire $100 \%$ of its American subsidiary KOMATSU DRESSER CO (Illinois) through the purchase of the $19 \%$ share still owned by INDRESCO INC (Texas). The deal, worth $\$ 38$ millions will be finalized in late September by the group's US-based subsidiary, KOMATSU AMERICA CORP, which owns $81 \%$ of KOMATSU DRESSER CO.

Faced with the challenges of the end of the century, we do not need less but more solidarity in Europe. Emanuele Gazzo knew this and fought admirably for this, with his heart, his pen and his keen intelligence.

The document with the most negative mean valence largely owes its score to using the word "war" and related vocabulary in multiple contexts:

Mr Woerner knew he had been "gambling his life away" when he ignored medical advice and insisted on chairing the NATO Council in February, when important decisions were taken regarding the war in Bosnia, said Mr Balanzino. He added that Mr Woerner was outraged as he lay in his own hospital bed to see the pictures of the spartan medical facilities in Sarajevo and Gorazde.

Tension rose again on Thursday in the "tuna war" pitting French fishermen against their Spanish counterparts for the past few weeks. The French Minister for Fisheries announced that five Spanish vessels had attacked four French vessels off the coast of Cap Breton and that the Spaniards had used gunfire, wounding a French fisherman. 
Mr Kok, the third Socialist Head of Government since the end of World War One, will be seconded by two Deputy Prime Ministers, Hans Dijkstal (VVD), who will serve as Home Affairs Minister, and Hans van Mierlo, leader of Democracy '66, who will become Foreign Minister.

And finally an AEB issue with mean valence zero (signalling complete neutrality), with a lead story on indirect taxation and news concerning legislation on posted workers, Brexit and European External Action Service appointments:

VAT agenda for EU in second half of 2017 The European Union may end up doing more work on matters of indirect taxation - with the European Commission's presentation of a major reform of the value-added tax (VAT) system - than on questions relating to corporate taxation in the second half of 2017.

Despite disagreements among countries of central and Eastern Europe in recent months on the review of the posted worker directive, the leaders of Austria, France, Slovakia and the Czech Republic restated their aim of reaching agreement at the Council by 23 October, the date of the next EPSCO Council (employment and social policy).

London wants data to continue to move freely on both sides of the Channel after Brexit British authorities believe data should continue to move freely between the European Union and United Kingdom after Brexit, and that a high level of personal data protection should be maintained. On the day the UK withdraws from the EU, the country will apply the framework regulation $(2016 / 679)$ on the data protection of natural persons, as well as the directive $(2016 / 680)$ on the handling of personal data for the purposes of preventing criminal offences.

On Monday 23 August, the European External Action Service (EEAS) announced in a press release that High Representative of the EU for Foreign Affairs and Security Policy Federica Mogherini has appointed a new deputy managing director and three heads of EU delegations.

The words classified by the AFINN dictionary as having the lowest valence are swear words (-5) and words such as "fraudulent", "catastrophic", "rape" and "tortured" (4). The most positive words $(+5)$ are "outstanding", "superb", "breathtaking", "hurrah" and "thrilled", each appearing in the corpus only once. The most frequent word with a positive score of 4 is "triumph". 